\title{
Thermodynamic properties and cloud droplet activation of a series of oxo-acids
}

\author{
M. Frosch ${ }^{1}$, A. A. Zardini ${ }^{1}$, S. M. Platt ${ }^{1}$, L. Müller ${ }^{2}$, M.-C. Reinnig ${ }^{2}$, T. Hoffmann ${ }^{2}$, and M. Bilde ${ }^{1}$ \\ ${ }^{1}$ Department of Chemistry, University of Copenhagen, Universitetsparken 5, 2100 Copenhagen, Denmark \\ ${ }^{2}$ Department of Inorganic Chemistry and Analytical Chemistry, Johannes Gutenberg-Universität Mainz, Duesbergweg 10-14, \\ 55128 Mainz, Germany
}

Received: 20 January 2010 - Published in Atmos. Chem. Phys. Discuss.: 10 February 2010

Revised: 8 June 2010 - Accepted: 15 June 2010 - Published: 2 July 2010

\begin{abstract}
We have investigated the thermodynamic properties of four aliphatic oxo-dicarboyxlic acids identified or thought to be present in atmospheric particulate matter: oxosuccinic acid, 2-oxoglutaric acid, 3-oxoglutaric acid, and 4-oxopimelic acid. The compounds were characterized in terms of their cloud condensation nuclei (CCN) activity, vapor pressure, density, and tendency to decarboxylate in aqueous solution. We deployed a variety of experimental techniques and instruments: a CCN counter, a Tandem Differential Mobililty Analyzer (TDMA) coupled with a laminar flow-tube, and liquid chromatography/mass spectrometry (LC/MS). The presence of the oxo functional group in the $\alpha$-position causes the vapor pressure of the compounds to diminish by an order of magnitude with respect to the parent dicarboxylic acid, while the CCN activity is similar or increased. Dicarboxylic acids with an oxo-group in the $\beta$ position decarboxylate in aqueous solution. We studied the effects of this process on our measurements and findings.
\end{abstract}

\section{Introduction}

Submicron sized aerosol particles in the Earth's atmosphere influence visibility (Elias et al., 2009), human health (Laden et al., 2006), and global climate (IPCC, 2007). Their chemical composition is complex and includes organic as well as inorganic molecules. The organic fraction has been estimated to account for $20 \%$ to $90 \%$ of the total aerosol mass (Kanaki-

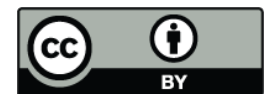

Correspondence to: M. Frosch (mia@kiku.dk) dou et al., 2005) and includes polyfunctional organic compounds.

Many polyfunctional organic compounds are both semivolatile and water soluble. Thus they can partition between the particle and the gas phase in the atmosphere. To correctly predict and control air-quality parameters, for example particulate matter loadings, a thorough understanding of this partitioning, and hence an understanding of basic thermodynamic properties such as vapor pressures, is needed. Moreover, due to their water solubility, polyfunctional organic molecules may play a role in the formation of cloud droplets and indirectly affect the global radiation budget. Here, knowledge of their ability to act as cloud condensation nuclei $(\mathrm{CCN})$ is critical.

One simple class of polyfunctional organic molecules is the dicarboxylic acids. Their $\mathrm{CCN}$ properties (e.g. Hori et al., 2003; Bilde and Svenningsson, 2004; Henning et al., 2005; Hartz et al., 2006), solid state (Bilde et al., 2003; Chattopadhyay and Ziemann, 2005; Cappa et al., 2007; Booth et al., 2009; Zardini and Krieger, 2009) as well as subcooled liquid state vapor pressures (Zardini et al., 2006; Koponen et al., 2007; Riipinen et al., 2007) have recently been studied quite extensively. Some of the more complex polyfunctional compounds in the atmosphere include the Humic Like Substances (HULIS) (Graber and Rudlich, 2006; Dinar et al., 2006; Sjogren et al., 2007) for which an understanding of their CCN activity is limited by a lack of information on basic physical properties such as molar weight and density.

In this work we focus on a series of molecules, which have one more functional group than dicarboxylic acids, but which have simpler structures than HULIS and other polyfunctional macromolecules, namely water soluble oxo-dicarboxylic

Published by Copernicus Publications on behalf of the European Geosciences Union. 
acids (aliphatic dicarboxylic acids which also have an oxogroup). Specifically, we have investigated thermodynamic properties of 4-oxopimelic, 2-oxoglutaric, 3-oxoglutaric, and oxosuccinic acids.

4-oxopimelic acid has been detected in particles in the polar atmosphere in concentrations up to $0.53 \mathrm{ng} / \mathrm{m}^{3}$ (Kawamura et al., 1995, 1996), in marine environments in concentrations up to $2.5 \mathrm{ng} / \mathrm{m}^{3}$ (Sakaguchi and Kawamura, 1994; Kawamura and Sakaguchi, 1999; Wang et al., 2006), and in trace amounts at suburban locations (Yokouchi and Ambe, 1986). 2-oxoglutaric acid and 4-oxopimelic acid have structural features similar to other compounds frequently detected in secondary organic aerosols and are thus considered as standards for organic dicarboxylic acids (Gao et al., 2004). Oxosuccinic acid has been studied previously and is also considered a surrogate standard for dicarboxylic acids (Rissman et al., 2007). Rissman et al. (2007) demonstrated that oxosuccinic acid particles can act as cloud condensation nuclei, but did not consider the effects of enolization and decarboxylation on cloud droplet formation. Such effects will be investigated in this work. Neither oxosuccinic acid nor 3-oxoglutaric acid have been detected in atmospheric aerosols. However, both compounds can react or decompose in the aqueous phase under ambient conditions to products that have been detected, e.g. pyruvic acid (Saxena and Hildemann, 1996). The main source of oxo-acids in the atmosphere is photochemical reactions from the parent dicarboxylic acid or from monovalent oxo-acids (Sakaguchi and Kawamura, 1994; Kawamura et al., 1996; Wang et al., 2006). Several sources have been suggested for dicarboxylic acids, mainly anthropogenic, but also biogenic sources and secondary production can be relevant (e.g. Kawamura and Kaplan, 1987; Rogge et al., 1993; Kawamura et al., 1995).

We have studied CCN and evaporative properties of four oxo-acids. For completeness, we have also examined cloud droplet activation of particles composed of two of the parent dicarboxylic acids: glutaric acid and pimelic acid. Finally, we have determined dissociation constants and densities.

\section{Theory}

\subsection{Chemistry of oxo-acids}

The chemical structures of the organic acids studied herein are shown in Fig. 1. Note that 3-oxoglutaric acid has the oxogroup in the $\beta$-position, and that 2 -oxoglutaric acid and 4oxopimelic acid have the oxo-group in the $\alpha$ - or $\gamma$-position, respectively. The oxo-group in oxosuccinic acid is in $\alpha$ position with respect to one acid group and $\beta$-position with respect to the other. Oxosuccinic acid undergoes the reactions of a $\beta$-oxo-acid described below and is therefore characterized as such in the following.

In this section we discuss the aqueous phase chemistry of oxo-acids with the oxo-group in the $\beta$-position. Most no- table is that $\beta$-oxo-acids can decarboxylate, i.e. lose $\mathrm{CO}_{2}$ (e.g. McMurry, 2003). In this work we have studied two such acids, namely 3-oxoglutaric acid and oxosuccinic acid. $\beta$-oxo-compounds will exist in three different forms when dissolved: keto-form, enol-form ( $\mathrm{Z}$ or $\mathrm{E}$ ), and as a hydrated gem-diol, see Fig. 2. The position of the equilibrium between these forms depends on various factors such as temperature, $\mathrm{pH}$, concentration, and the polarity of the solvent. In polar solvents such as water, at room temperature and $\mathrm{pH}$ near or slightly below 7 , studies indicate that oxosuccinic acid is mainly in the keto-form, the abundance of which is 70-90\% (Pogson and Wolfe, 1972; Kokesh, 1976; Emly and Leussing, 1981). The enol- and the hydrated form comprise the remaining $10-30 \%$. In less polar solvents such as methanol, a shift towards the enol-form is observed (Kumler et al., 1962; Kokesh, 1976). Conversion between the keto- and the enolform is catalyzed by $\mathrm{H}_{3} \mathrm{O}^{+}, \mathrm{OH}^{-}$(McMurry, 2003), and certain enzymes (Loewus et al., 1955). The position of the equilibrium between the three forms is likely to influence vapor pressure of particles containing oxosuccininc acid, since the alcohol groups of the enol- or hydrated forms are better acceptors/donors of hydrogen bonds than the oxo-group of the keto-form. The keto-form is therefore likely to have the highest vapor pressure, although the magnitudes of the differences in vapor pressure between the three forms are unknown.

Of the three forms, only the keto-form will decarboxylate (Steinberger and Westheimer, 1951; Kosicki et al., 1964). Decarboxylation may be catalyzed by enzymes (Kornberg and Ochoa, 1948), various metal ions (Krebs, 1942; Kornberg and Ochoa, 1948) such as lithium (Kosicki et al., 1964), copper (Raghavan and Leussing, 1976), zinc (Guzman and Martin, 2008), and magnesium (Kosicki and Lipvac, 1964), but it will also happen spontaneously in aqueous solution (Krebs, 1942; Kornberg and Ochoa, 1948). Figure 3 shows the spontaneous decarboxylation of oxosuccinic acid and the equilibrium between the enol and the keto-form of the resulting pyruvic acid (Kosicki and Lipvac, 1964).

Oxo-dicarboxylic acids are divalent and, depending on $\mathrm{pH}$, the acids will exist in their neutral form (HOOC-R-COOH), as a mono-anion (HOOC-R-COO ${ }^{-}$) or as a di-anion $\left({ }^{-} \mathrm{OOC}-\right.$ $\mathrm{R}-\mathrm{COO}^{-}$). The mono-anion of oxosuccinic acid decarboxylates much faster than the di-anion (by a factor 4) and the neutral form (by a factor 44) (Buldain et al., 1985). At room temperature, the rate is therefore barely measurable in very acidic $(\mathrm{pH}<1)$ or very alkaline solutions $(\mathrm{pH}>13)$, where oxosuccininc acid is stable (Krebs, 1942). The maximum rate of decarboxylation is found within that range. For example, at $\mathrm{pH}=4$ and a temperature of $20^{\circ} \mathrm{C}$, the decomposition of the keto-form was found to be between $6 \%$ and $18 \%$ per hour (Krebs, 1942). The uncertainty in the rate may be ascribed to traces of impurities catalyzing the reaction (Krebs, 1942).

$\beta$-oxo-acids can also undergo aldol-reactions to yield products such as citroylformic acid (Buldain et al., 1985), shown in Fig. 4. Figure 5 shows the aldol-reaction of pyruvic 
<smiles>O=C(O)CCCC(=O)O</smiles>

succinic acid<smiles>O=C(O)CC(=O)C(=O)O</smiles>

oxosuccinic acid<smiles>O=C(O)CCCC(=O)CCC(=O)O</smiles>

4-oxopimelic acid<smiles>O=C(O)CCCCCCC(=O)O</smiles>

pimelic acid<smiles>O=C(O)CCCCC(=O)O</smiles>

glutaric acid<smiles>O=C(O)CCC(=O)C(=O)O</smiles>

2-oxoglutaric acid<smiles>O=C(O)CC(=O)CC(=O)O</smiles>

3-oxoglutaric acid

Fig. 1. Chemical structures of the molecules studied in this work. Succinic acid is added for completeness.<smiles>C#CC#C</smiles>

Keto<smiles>C#CC#CC(=O)C=C(O)C(=O)O</smiles>

Enol<smiles>O=C(O)CC(O)(O)C(=O)O</smiles>

Hydrated

Fig. 2. The three forms of oxosuccinic acid in aqueous solution.

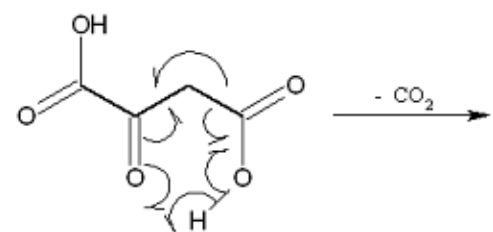

a-hydroxyacrylic acid<smiles>C=C(O)C(=O)O</smiles><smiles>C=C</smiles><smiles>CC(=O)C(=O)O</smiles>

Pyruvic acid

keto-form

Fig. 3. Decarboxylation of oxosuccinic acid.

acid (Buldain et al., 1985), which is a major decarboxylation product of oxosuccinic acid. As mentioned above, only the keto-form of $\beta$-oxo-acid will decarboxylate. Since the relative concentration of the keto-form is dependent on solvent, temperature, and $\mathrm{pH}$, the rate of decarboxylation and the con- centrations of the decomposition and reaction products from Fig. 3, Fig. 4 and Fig. 5 are also dependent on these factors.

3-oxoglutaric acid (acetonedicarboxylic acid) has also been observed to decarboxylate. The solid compound rapidly decomposes to $\mathrm{CO}_{2}$ and acetone upon heating (von 


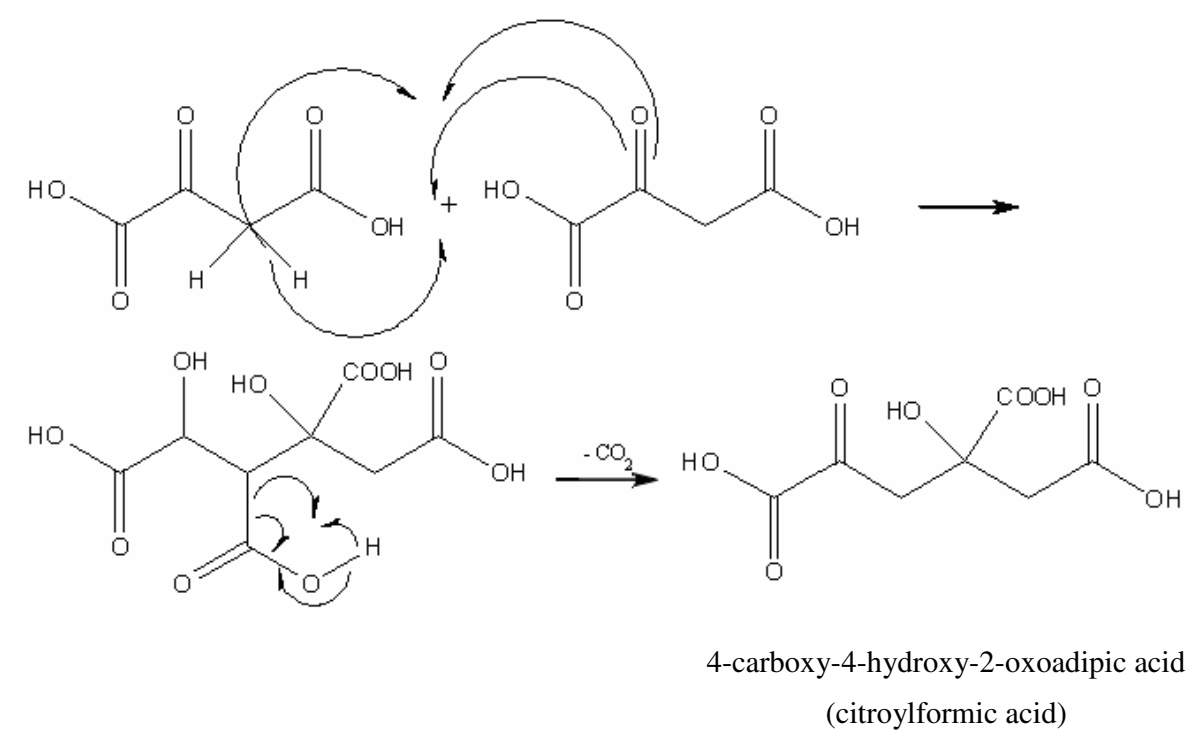

Fig. 4. Aldol reactions of oxosuccinic acid.<smiles>CC(=O)C(=O)OC(=O)C(=O)OCC(C)(O)C(=O)O</smiles>

4-hydroxy-4-methyl-2-oxoglutaric acid

Fig. 5. Aldol reaction of puruvic acid, the product of decarboxylation of oxosuccinic acid.

Pechmann, 1884), but at lower temperature this reaction is slow, so the compound is stable at, for example, room temperature (Wiig, 1929). In aqueous solution, the decarboxylation of 3-oxoglutaric acid is catalyzed by e.g. aniline, hydrochloric acid, inorganic salts, and metal ions (Wiig, 1928; Prue, 1952; Larson and Lister, 1968).

Like oxosuccinic acid, 3-oxoglutaric acid can exist in the keto-form, enol-from, or as a gem-diol. The keto-form, the only one capable of decarboxylating, is dominant at room temperature in aqueous solution (Wiig, 1928). The products and kinetics of 3-oxoglutaric acid have not been thoroughly studied, but the decomposition to acetone occurs in two steps (Prue, 1952; Hay and Bond, 1967), as shown in Fig. 6. The stability of 3-oxoglutaric acid in aqueous solution depends on $\mathrm{pH}$ because the neutral molecule decarboxylates slower than the mono-anion, but much faster than the di-anion (Larson and Lister, 1968). Assuming decarboxylation to be a first order $\mathrm{pH}$ dependent reaction, the rate constant can be estimated to be $\sim 10^{-4} \mathrm{~min}^{-1}$ at room temperature and $\mathrm{pH}=7$ (Larson and Lister, 1968).

\subsection{Cloud droplet activation}

Critical supersaturations were calculated using Köhler theory. Limited solubility was not accounted for. Following the equations provided in Bilde and Svenningsson (2004), the minimum solubility necessary for particles with diameters in the range $30-130 \mathrm{~nm}$ to be fully dissolved was calculated for each of the studied compounds. The solubilities of the dicarboxylic acids are available in literature (e.g. Saxena and Hildemann, 1994; Lide, 2004) and the solubilities of the oxo-acids were tested in the laboratory by simply dissolving known amounts (larger than the calculated minimum amount) of acid in water. For each compound, the actual solubility was found to be above the calculated solubility limit

The Köhler equation (Köhler, 1936) gives the ratio, $S$, of the equilibrium vapor pressure of water over an aqueous solution droplet surface compared to the equilibrium vapor pressure of pure water over a flat surface. Here we express it as follows (Seinfeld and Pandis, 1998):

$$
S=a_{\mathrm{w}} \cdot \exp \left(\frac{4 M_{\mathrm{w}} \sigma_{1, \mathrm{air}}}{\operatorname{RT} \rho_{l} D_{\mathrm{p}}}\right),
$$



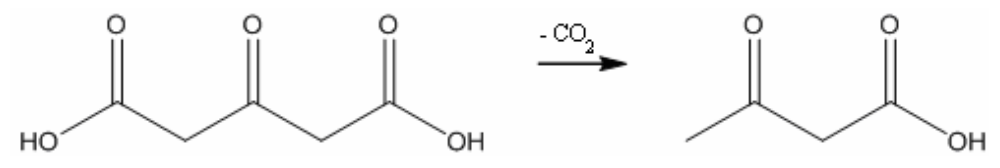

3-oxobutanoic acid

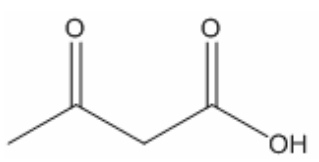

3-oxobuctanoic acid
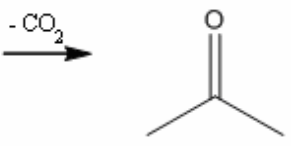

acetone

Fig. 6. The two steps in the decarboxylation of 3-oxoglutaric acid.

where $a_{\mathrm{w}}$ is the water activity, $M_{\mathrm{w}}$ is the molar weight of water, $\sigma_{1, \text { air }}$ is the air-liquid surface tension, $R$ is the ideal gas constant, $T$ is the absolute temperature, $\rho_{1}$ is the density of the solution, and $D_{\mathrm{p}}$ is the droplet diameter. In this work we approximate $\rho_{1}$ to the density of pure water $\left(997.96 \mathrm{~kg} \mathrm{~m}^{-3}\right)$. The temperature is assumed to be room temperature, $T_{\text {room }}=298.15 \mathrm{~K}$. Information about the surface tension is only available for some of the parent dicarboxylic acids (Varga et al., 2007), which are not strongly surface active. However, a good agreement between measurements and Köhler theory is attained using the surface tension of pure water for particles containing the salts of fatty acids (Prisle et al., 2008). Therefore, the surface tension $\sigma_{1, \text { air }}$ is here approximated by the surface tension of pure water $\left(0.07275 \mathrm{~N} \mathrm{~m}^{-1}\right)$. The maximum of $S$ (as a function of $D_{\mathrm{p}}$ ) defines the so-called critical supersaturation, $\mathrm{SS}_{\mathrm{c}}$.

Although we know that oxosuccinic acid and 3oxoglutaric acid can undergo chemical reactions in the aqueous phase, as a first approximation critical supersaturations were calculated assuming that no such reactions occurred. Following e.g. Bilde and Svenningsson (2004), water activities in this work were calculated as follows:

$a_{\mathrm{w}}=\frac{n_{\mathrm{w}}}{n_{\mathrm{w}}+v_{\mathrm{i}} n_{\mathrm{i}}}=\left(1+v_{\mathrm{i}} \frac{\rho_{\mathrm{i}} M_{\mathrm{w}}}{\rho_{\mathrm{w}} M_{\mathrm{i}}} \frac{D_{\mathrm{p}}^{3}-d_{0}^{3}}{d_{0}^{3}}\right)^{-1}$.

The subscripts $i$ and $w$ denote the solute and water, respectively. $n$ is the number of moles, $\rho_{\mathrm{i}}$ is the particle density, $d_{0}$ is the initial dry size of the particle, and $v_{\mathrm{i}}$ is the van't Hoff factor. The van't Hoff factor accounts for non-ideality and the dissociation of species $i$. Neglecting non-ideality, the van't Hoff factor can be calculated from the degree of dissociation of the acid.

Dicarboxylic acids can dissociate in aqueous solution:

$$
\begin{aligned}
& \mathrm{HCOO}-\mathrm{R}-\mathrm{COOH} \rightarrow \mathrm{HCOO}-\mathrm{R}-\mathrm{COO}^{-}+\mathrm{H}^{+} \\
& \mathrm{HCOO}-\mathrm{R}-\mathrm{COO}^{-} \rightarrow{ }^{-} \mathrm{COO}-\mathrm{R}-\mathrm{COO}^{-}+\mathrm{H}^{+}
\end{aligned}
$$

Below we show that for the acids studied in this work it is reasonable to neglect the second dissociation step and consider the acids monovalent. For a monovalent acid the van't Hoff factor can be calculated as a function of acid concentration as follows:

$v_{\mathrm{i}}=1+\omega_{\mathrm{i}}=1+\frac{-K_{\mathrm{a} 1}+\sqrt{K_{\mathrm{a} 1}^{2}+4 K_{\mathrm{a} 1} \cdot c_{\mathrm{i}}}}{2 c_{\mathrm{i}}}$,

where $\omega_{\mathrm{i}}$ is the dissociated fraction and $c_{\mathrm{i}}$ is the total concentration of the dicarboxylic acid $i$ (molarity scale). Values of $\mathrm{pK}_{\mathrm{a} 1}\left(-\log K_{\mathrm{a} 1}\right)$ are given in Table 1, and Fig. 7 shows van't Hoff factors as a function of acid concentration for different values of $K_{\mathrm{a} 1}$.

Figure 8 shows the van't Hoff factor at activation for different values of $\mathrm{pK}_{\mathrm{a} 1}$ for a monovalent model acid with molar mass $M=150 \mathrm{~g} / \mathrm{mol}$ and density $\rho=1.5 \mathrm{~g} / \mathrm{cm}^{3}$. The van't Hoff factor for such an acid with $\mathrm{pK}_{\mathrm{a} 1}$ larger than 4 is close to 1 , which justifies ignoring dissociation for these acids. For acids with a smaller $\mathrm{pK}_{\mathrm{a} 1}$, dissociation based on the acid constant should be taken into account.

To justify neglecting the second dissociation step, we consider an acid with the same properties as oxosuccinic acid, the strongest of the studied acids. We compare dissociation at activation of two dry particles with initial sizes of $40 \mathrm{~nm}$ and $90 \mathrm{~nm}$, respectively (representative of the size range of dry particles studied herein). To estimate the acid concentration in the droplet at activation, we assume that the van't Hoff factor at activation is 1.3 for both particles. This value is calculated from actual measurements of critical supersaturation, which will be presented in Sect. 4.4. The critical supersaturation of particles with diameters of $40 \mathrm{~nm}$ and $90 \mathrm{~nm}$ were determined and Köhler theory was fitted to these experimental results by varying the van't Hoff factor. Best fits were obtained with van't Hoff factors of 1.28 and 1.33 , respectively. A van't Hoff factor of 1.3 also seems a reasonable estimate based on Fig. 8 using a $\mathrm{pK}_{\mathrm{a} 1}$ of 1.9. For the $40 \mathrm{~nm}$ particles, the total acid concentration 
Table 1. Chemical and physical properties used in Köhler theory and evaporation analysis.

\begin{tabular}{|c|c|c|c|c|c|c|c|c|}
\hline Compound & $\begin{array}{r}\text { Density } \\
\mathrm{g} / \mathrm{ml}\end{array}$ & $\mathrm{pKa}_{1}$ & $\mathrm{pKa}_{2}$ & $\begin{array}{r}M \\
\mathrm{~g} / \mathrm{mol}\end{array}$ & $\begin{array}{r}\sigma_{\mathrm{ii}}^{\mathrm{f}} \\
\AA\end{array}$ & $\begin{array}{r}\varepsilon_{\mathrm{ii}} / \\
k_{\mathrm{B}}^{\mathrm{f}} \mathrm{K}\end{array}$ & $\begin{array}{r}V c^{\mathrm{g}} \\
\mathrm{cm}^{3} / \mathrm{mol}\end{array}$ & $\begin{array}{r}T_{\mathrm{m}}^{\mathrm{h}} \\
\mathrm{K}\end{array}$ \\
\hline 2-oxoglutaric acid & $1.61^{\mathrm{a}}$ & $2.4 \pm 0.2^{\mathrm{a}}$ & $4.9 \pm 0.5^{\mathrm{a}}$ & 146.11 & 6.038 & 745.9 & 370 & $387-389$ \\
\hline 3-oxoglutaric acid & $1.49^{\mathrm{a}}$ & $2.74^{\mathrm{e}}$ & $3.72^{\mathrm{e}}$ & 146.11 & 6.038 & 777.6 & 370 & 405 \\
\hline \multirow[t]{3}{*}{ oxosuccininc acid } & $1.76^{\mathrm{a}}$ & $2.22^{\mathrm{b}}$ & $3.89^{\mathrm{b}}$ & 132.08 & 5.722 & 833.3 & 315 & 434 \\
\hline & & $2.56^{\mathrm{c}}$ & $4.37^{c}$ & & & & & \\
\hline & & $1.9^{\mathrm{d}}$ & $4.0^{\mathrm{d}}$ & & & & & \\
\hline 4-oxopimelic acid & $1.49^{\mathrm{a}}$ & $4.7^{\mathrm{a}}$ & - & 174.15 & 5.722 & 834.2 & 315 & $415-417$ \\
\hline Pimelic acid & 1.281 & 4.71 & - & 160.17 & 6.56 & 722.2 & 475 & $376-378$ \\
\hline Glutaric acid & 1.424 & 4.31 & - & 132.12 & 6.01 & 708.8 & 365 & $368-371$ \\
\hline Succinic acid & 1.556 & 4.21 & 5.64 & 118.09 & 5.69 & 885.41 & 310 & 461 \\
\hline
\end{tabular}

a This study.

b Tate et al. (1964).

c Pedersen (1952).

d Emly and Leussing (1981).

e Prue (1952).

f $\sigma_{\mathrm{ii}}=0.841 \cdot V c^{1 / 3}, \varepsilon_{\mathrm{ii}} / k_{\mathrm{B}}=1.92 \cdot T_{\mathrm{m}}$. The Lennart-Jones parameters $\sigma_{\mathrm{i}, \text { air }}$ and $\varepsilon_{\mathrm{i}, \text { air }} / k_{\mathrm{B}}$ are estimated as follows: $\sigma_{\mathrm{i}, \text { air }}=1 / 2 \cdot\left(\sigma_{\mathrm{ii}}+\sigma_{\mathrm{air}}\right)$, $\varepsilon_{\mathrm{i}, \text { air }} / k_{\mathrm{B}}=\left(\varepsilon_{\mathrm{ii}} \cdot \varepsilon_{\mathrm{air}}\right)^{1 / 2}$, where $\sigma_{\mathrm{air}}=3.617 \AA$ and $\varepsilon_{\mathrm{air}} / k_{\mathrm{B}}=97 \mathrm{~K}$ (Bird et al., 1960). $k_{\mathrm{B}}$ is the Boltzmann constant.

$\mathrm{g}$ Critical volume, Vc, estimated using the group contribution method by Lyderson et al. (1955).

${ }^{\mathrm{h}}$ Melting points were obtained from producers and confirmed by measurements using a capillary melting point apparatus.

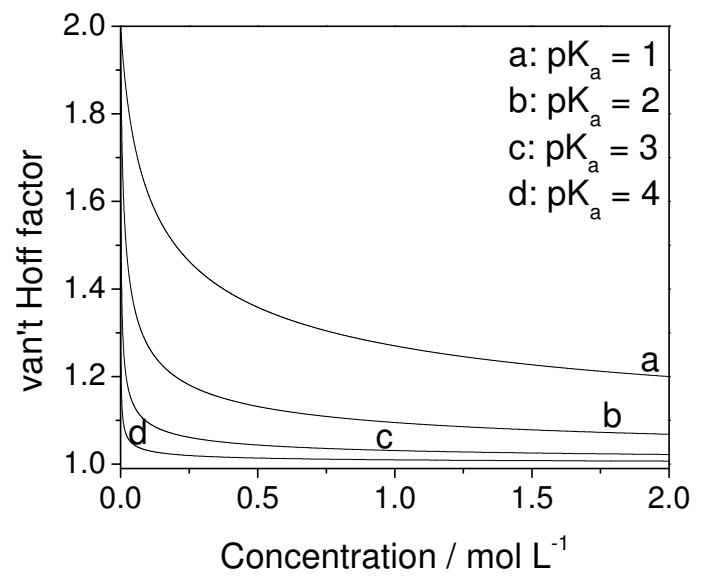

Fig. 7. Van't Hoff factor as a function of concentration (calculated according to Eq. 3) for four monovalent acids with different pKavalues.

(the sum of dissociated and undissociated acid) is $0.17 \mathrm{M}$, of which $0.040 \mathrm{M}(24 \%)$ has dissociated once and exists as the mono-anion, and $0.00077 \mathrm{M}$ (less than $0.5 \%$ ) has dissociated twice and exists as the di-anion (using $\mathrm{pK}_{\mathrm{a} 1}=1.9$ and $\mathrm{pK}_{\mathrm{a} 2}=4.0$ ). For the $90 \mathrm{~nm}$ particles, the total acid concentration is $0.053 \mathrm{M}$, of which $0.020 \mathrm{M}$ or $38 \%$ has dissociated once and exists as the mono-anion, and $0.0012 \mathrm{M}$ or $2.6 \%$ has dissociated twice and exists as the di-anion. In both cases it is seen that the first step of the acid dissociation is significant, whereas the second step is negligible when calculating van't

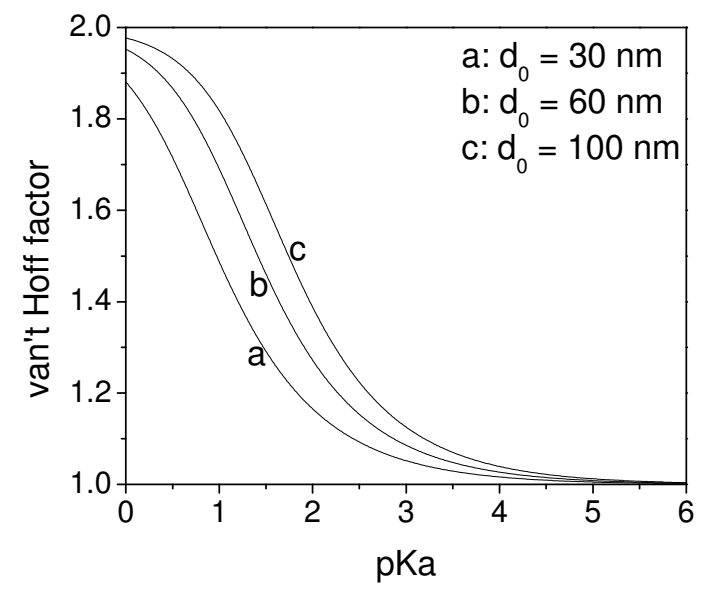

Fig. 8. Van't Hoff factor as a function of $\mathrm{pK}_{\mathrm{a}}$ at the critical droplet diameter of three particles with different dry sizes, composed of a model monovalent acid with molar mass $M=150 \mathrm{~g} / \mathrm{mol}$ and density $\rho=1.5 \mathrm{~g} / \mathrm{ml}$.

Hoff factors. Oxosuccinc acid is the most acidic compound of the study. Therefore, the second step of dissociation will be even less significant for any of the other studied oxo-acids.

The relationship between dry particle diameter and critical supersaturation has also been described by the single hygroscopicity parameter, $\kappa$, introduced by Petters and Kreidenweis (2007):

$$
\frac{1}{a_{\mathrm{w}}}=1+\kappa \frac{V_{\mathrm{s}}}{V_{\mathrm{w}}},
$$


where $V_{\mathrm{s}}$ is the solute volume (dry particle volume) and $V_{\mathrm{w}}$ is the water volume. A higher $\kappa$ means a higher hygroscopicity.

\subsection{Evaporation}

Solid state vapor pressures were inferred from measurements of evaporation rates using the approach of Bilde and Pandis (2001), Bilde et al. (2003), and Mønster et al. (2004), summarized below. We assume that the particles are spherical, their surface free energy is isotropic, and that the partial pressure of a species $i$ far from the particle surface is negligible. Furthermore we neglect latent heat effects.

In brief, the vapor pressure $p_{\mathrm{i}}^{0}$ of compound $i$ over a flat surface can be obtained from particle diameters before $\left(D_{\mathrm{i}}\right)$ and after $\left(D_{\mathrm{f}}\right)$ evaporation, evaporation time $(\Delta t)$, and surface free energy between the solid and the gas phase $\left(\sigma_{\mathrm{s}, \mathrm{air}}^{\mathrm{i}}\right)$ as follows (Rader and McMurry, 1987):

$$
\begin{aligned}
p_{\mathrm{i}}^{0}=- & \frac{\rho_{\mathrm{i}} \mathrm{RT}}{4 D_{\mathrm{i}, \text { air }} \Delta t M_{\mathrm{i}}} \cdot \int_{D i}^{D f} \frac{D_{\mathrm{p}}}{F}\left(K n_{\mathrm{i}}, \alpha_{\mathrm{i}}\right) \\
& \cdot \exp \left(\frac{-4 \sigma_{\mathrm{s}, \text { air }}^{\mathrm{i}} M_{\mathrm{i}}}{D_{\mathrm{p}} \rho_{\mathrm{i}} \mathrm{RT}}\right) d D_{\mathrm{p} .}
\end{aligned}
$$

It is assumed that surface free energy, $\sigma_{\mathrm{s}, \mathrm{i}}^{\mathrm{i}}$, is independent of particle size. $R$ is the gas constant, $T$ is the temperature, $M_{\mathrm{i}}$ is the molar mass of species $i, \rho_{\mathrm{i}}$ is the density of $i$, and $D_{\mathrm{i}}$,air is the diffusivity of $i$ in air. We calculate $D_{\mathrm{i} \text {,air }}$ as described in Bird et al. (1960) using the physical properties and LennardJones parameters in Table 1:

$D_{\mathrm{i}, \text { air }}=5.9542 \cdot 10^{-24} \frac{\sqrt{T^{3}\left(\frac{1}{M_{\mathrm{i}}}+\frac{1}{M_{\text {air }}}\right)}}{p \sigma_{\mathrm{i}, \mathrm{air}}^{2} \Omega_{\mathrm{i}, \text { air }}}$

where $M_{\text {air }}=0.0289 \mathrm{~kg} / \mathrm{mol}$ is the molar weight of air, and $p$ is total pressure (Pa). The collision integral $\Omega_{\mathrm{i} \text {,air }}$ is obtained from Bird et al. (1960), where it is tabulated as a function of $k_{B} T / \varepsilon_{\mathrm{i}, \text { air }}$ (see Table 1). $\sigma_{\mathrm{i}, \text { air }}$ can be determined as described in Table 1.

We use the transition regime correction suggested by Fuchs and Sutugin (1971):

$F\left(K n_{\mathrm{i}}, \alpha_{\mathrm{i}}\right)=\frac{1+K n_{\mathrm{i}}}{1+0.3773 K n_{\mathrm{i}}+1.33 K n_{\mathrm{i}}\left(1+K n_{\mathrm{i}}\right) / \alpha}$,

where $K n_{\mathrm{i}}=2 \lambda_{\mathrm{i}} / D_{\mathrm{p}}$ is the Knudsen number. An alternative formulation suggested by Bademosi and Lui can be found in Zhang et al. (1993) and was used for the sensitivity analysis described below. Since we do not have information about the value of the accommodation coefficient $(\alpha)$, we follow the recommendation by Kulmala and Wagner (2001) and assume $\alpha$ to be unity.

\section{Experimental}

Chemicals were obtained from commercial sources: oxosuccinic acid (Aldrich, 98\%), glutaric acid (Aldrich, 99\%), 2-oxoglutaric acid (Aldrich, 98\%), 3-oxoglutaric acid (Alfa Aesar, 97\%), pimelic acid (Fluka, >99\%), 4-oxopimelic acid (Fluka, >99.0\%) and used as received. Aqueous solutions were prepared by dissolving the chemicals in doubledeionized water purified using a MilliQ Plus Ultrapure water system. All acids were easily dissolved. Typically, the concentration of the aqueous solutions used for atomization were $\sim 0.2 \mathrm{~g} / \mathrm{L}$ in the $\mathrm{CCN}$ experiments and $\sim 0.1 \mathrm{~g} / \mathrm{L}$ in the evaporation experiments. High pressure, dried and purified air was used in all experiments.

\section{1 pKa values and densities}

The acid strengths of the 2-oxoglutaric acid and 4oxopimelic acid were estimated by titration with $\mathrm{NaOH}$ using a combination electrode (Radiometer Analytical), calibrated using two buffers with $\mathrm{pH} 4$ and 7 , and connected to a PHM82 Standard pH-meter. Titration curves can be found in Supplementary Material; the uncertainties on pKavalues represent $10 \%$ (estimated). The acid strength of $4-$ oxopimelic acid could not be found in literature. The acid strengths of 2-oxoglutaric has been reported as $\mathrm{pK}_{\mathrm{a} 1}=2.47$ and $\mathrm{pK}_{\mathrm{a} 2}=4.68$ (Lide, 2004) and are thus within experimental error of the values determined in this study $\left(\mathrm{pK}_{\mathrm{a} 1}=2.4 \pm 0.2\right.$ and $\mathrm{pK}_{\mathrm{a} 1}=4.9 \pm 0.5$; see Table 1).

Densities of the oxo-acids were estimated by mixing two liquids of different known densities and placing a few acid crystals in the mixture. The two liquids were chosen based on the following criteria: the oxo-acids were virtually insoluble in both liquids, and one liquid had a higher density than the oxo-acid (i.e., when placed in this liquid, the oxo-acid crystals floated to the top), and the other had a lower density (i.e., the oxo-acid crystals sank to the bottom). The liquids were mixed in such proportions that the oxo-acid crystals remained suspended. The density of the mixture was then equal to the density of the crystals and could be determined by weighing a known volume of the liquid.

Table 2 summarizes the chosen liquids and the resulting estimates of densities for the oxo-acids. The measurement of densities was repeated 3-10 times for each acid and uncertainties on the density represent $1-2 \%$.

\subsection{Evaporation rates}

Evaporation rates were measured using the modified tandem differential mobility analyzer system (TDMA), previously described in Bilde et al. (2003) (see also Mønster et al., 2004; Koponen et al., 2007; and Riipinen et al., 2007, for results obtained with the laminar flow reactor used in this work; see also Bilde and Pandis, 2001, for the use of a similar TDMA). A monodisperse aerosol distribution (selected with 
Table 2. Measured densities of the four oxo-compounds and the liquids used to determine density.

\begin{tabular}{llll}
\hline Chemical compound & Liquid 1 & Liquid 2 & Density $\left(\mathrm{kg} \mathrm{m}^{-3}\right)$ \\
\hline oxosuccininc acid & Methane dibromide & Methane tetrachloride & $1760 \pm 7$ \\
2-oxoglutaric acid & Methane trichloride & Methane tetrachloride & $1610 \pm 6$ \\
3-oxoglutaric acid & Methane trichloride & Methane dibromide & $1490 \pm 6$ \\
4-oxopimelic acid & Methane trichloride & Methane tetrachloride & $1490 \pm 2$ \\
\hline
\end{tabular}

a Hauke-type differential mobility analyzer (DMA) with an average width of the distribution of 1.09) evaporates for a given residence time in a $3.5 \mathrm{~m}$ long laminar flow-tube. The size distribution of the aerosol particles is measured immediately after the Hauke-type DMA, at the entrance to the flowtube, at four different ports along the length of the flow-tube as well as at the end of the tube using a second DMA (TSI 3081) coupled with a particle counter (UFCPC, TSI 3776). The Hauke DMA was operated in non-recirculating mode with sheath and aerosol volumetric flow rates of $31 / \mathrm{min}$ and $0.3 \mathrm{l} / \mathrm{min}$, respectively. The aerosol flow through the laminar flow-tube was $0.31 / \mathrm{min}$ and to maximize the residence time in the flow reactor, no sheath air was added. The second DMA was operated in non-recirculating mode with a sheath air to aerosol flow ratio of $3: 0.3 \mathrm{l} / \mathrm{min}$.

Here the TDMA system was used to measure the evaporation rates of submicrometer sized particles of oxo-acids under dry conditions. Aerosols were generated by atomization of aqueous solutions of the individual oxo-acids in a constant output atomizer (TSI 3076) operated in non-recirculating mode followed by drying in two silica gel diffusion dryers. The crystalline particles were neutralized by exposing them to a Kr-85 bipolar ion source (TSI, 3077A Aerosol Neutralizer). Experiments were performed at ambient temperature and pressure and relative humidities less than $6 \%$. We did not perform direct measurements on the physical state of the particles. The assumption of dry particles is based on the experimental conditions, namely the use of silica gel dryers and the low water vapor in the gas phase. Moreover, the vapor pressure values are a posteriori consistent with the oddeven alternation effect observed in similar studies using the same apparatus (Bilde et al., 2003). Measurements of hygroscopicity and physical state transitions of the oxo-acids are lacking in the literature, and would be therefore desirable to assure we are dealing with dry particles. Number concentration in the flow-tube ranged from $2 \times 10^{4}$ to $6 \times 10^{4} \mathrm{~cm}^{-3}$ on average, depending on the experiment.

For calculation of vapor pressures we use Eq. (5), with initial and final diameters measured at port 1 and port 4 . Since information about surface free energies of organic molecules is limited, we rely on experience and data analysis from previous studies (Bilde and Pandis, 2001; Bilde et al., 2003) to infer a range of surface free energies and corresponding vapor pressures.

\subsection{CCN measurements}

The experimental system used for measuring $\mathrm{CCN}$ properties has been described in detail previously (Bilde and Svenningsson, 2004; Svenningsson et al., 2006) and will only be discussed briefly here. Critical supersaturations were determined using a static thermal-gradient diffusion type Cloud Condensation Nucleus Counter (CCNC, University of Wyoming, CCNC-100B). Supersaturation in the CCNC was calibrated with ammonium sulphate particles as described for example by Bilde and Svenningsson (2004). Water activity of ammonium sulfate was calculated using data from Young and Warren (1992) for molalities less than $1 \mathrm{~mol} / \mathrm{kg}$. For more concentrated solutions, the water activity was determined using data from Low (1969). More information about the calibration is available in the Supplementary Material. The experiments described herein were carried out over a number of months and several calibrations were performed. For each experiment the most recent calibration was used.

Particles were generated using a constant output atomizer (TSI, 3076). After drying in diffusion dryers and dilution with dry, purified air to relative humidities in the range $3.8-12.6 \%$, the particles entered a neutralizer (TSI, 3012) and DMA (TSI, 3080 Electrostatic Classifier) with a ratio of aerosol air to sheath air in the range of 0.037:1 to 0.11:1. The exiting dry quasi-monodisperse aerosol flow was diluted with dry, purified air by a factor of approximately 0.34:3.5 to 1.1:3.5 and split between the CCNC and a condensation particle counter (TSI, 3010), which measured the total concentration of condensation nuclei, [CN]. Supersaturations inside the CCNC were scanned over the range $0.2-2 \%$. In each supersaturation step, the number concentration of activated particles, $[\mathrm{CCN}]$, was measured. Figure 9 shows an example of the activated fraction, $[\mathrm{CCN}] /[\mathrm{CN}]$ plotted as a function of supersaturation inside the CCNC. The data points were fitted using the relaxed step function described by Svenningsson and Bilde (2008) and also used by Kristensson et al. (2010). CCN measurements were performed on several different days using different atomizing solutions and were found to be reproducible. Fresh aqueous solutions for the atomizer were prepared each morning and used the entire day. 


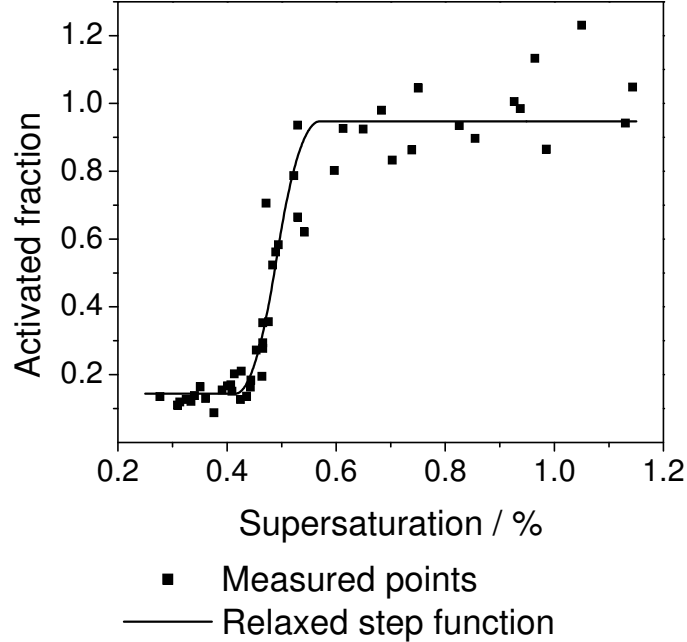

Fig. 9. The activated fraction as a function of supersaturation for particles with a diameter of $60 \mathrm{~nm}$ composed of 2-oxoglutaric acid. The data has been calibrated and is fitted to a relaxed step function.

Single component particles of all the oxo-acids were investigated, as well as two of the parent compounds, glutaric and pimelic acid. As both of these molecules are highly water soluble, cloud droplet activation is not limited by solubility. Pure particles of succinic acid were not studied since we have previously shown that their activation is limited by solubility and thus very sensitive to even small amounts of soluble impurities (Bilde and Svenningsson, 2004).

\section{$3.4 \mathrm{LC} / \mathrm{MS}$}

For the investigation of the four above mentioned oxo-acids via Liquid Chromatography/Mass Spectrometry (LC/MS) $10 \mathrm{mg}$ of each substance was dissolved in $10 \mathrm{ml}$ of an acetonitrile/water (1:10) solution. Subsequently, the solution was diluted with water by a factor 100 . The obtained solution was investigated by HPLC-ESI-IT/MS measurements, which were performed with a HCT-Plus ion trap mass spectrometer (Bruker-Daltonics GmbH, Bremen, Germany) equipped with a HPLC-System (Agilent 1100 series, auto sampler, gradient pump and degasser, Agilent Technologies $\mathrm{GmbH}$, Germany) and an Atlantis T3 C18 $150 \mathrm{~mm} \times 2.0 \mathrm{~mm}$ column with $3 \mu \mathrm{m}$ particle size (Waters, Germany).

The eluents were HPLC grade water (Milli-Q water system, Millipore, Bedford, USA) with $0.1 \%$ formic acid and $2 \%$ acetonitrile (eluent $\mathrm{A}$ ) and acetonitrile with $2 \%$ water (eluent B). The gradient of the mobile phase, with a flow of $0.2 \mathrm{~mL} / \mathrm{min}$, was chosen as follows: starting with $0 \% \mathrm{~B}$, gradient to $100 \% \mathrm{~B}$ in $30 \mathrm{~min}$, isocratic for $5 \mathrm{~min}$ and gradient to $0 \% \mathrm{~B}$ in $5 \mathrm{~min}$. The column was equilibrated at $0 \%$ B for $20 \mathrm{~min}$. The LC System was directly connected to the electrospray ion source with the following setup: nebulizer pressure $2200 \mathrm{mbar}$, dry gas flow $10 \mathrm{~L} / \mathrm{min}$, dry gas tempera- ture $365^{\circ} \mathrm{C}$, spray voltage $4500 \mathrm{~V}$. The ion optic of the mass spectrometer, operated in the negative ion mode, was optimized for adipic acid (negative ion mode $\mathrm{m} / \mathrm{z}$ 145, positive ion mode $\mathrm{m} / \mathrm{z}$ 147). MS/MS-experiments were conducted with an isolation width of $0.5 \mathrm{Da}$.

\section{Results and discussion}

Vapor pressure, surface free energy, critical supersaturation of dry particles with a diameter of $60 \mathrm{~nm}$, and average $\kappa$ values are summarized in Table 4 for all investigated compounds.

\subsection{Glutaric acid}

The CCN activity of glutaric acid particles has previously been studied experimentally (Cruz and Pandis, 1997; Prenni et al., 2001; Raymond and Pandis, 2002; Hori, 2003; Kumar et al., 2003), but results tend to deviate significantly from theory and from each other. Most recently this was discussed by Varga et al. (2007). It has been suggested that glutaric acid particles are unstable and that fissioning or restructuring to a smaller size can happen between the DMA and CCNC (Kumar et al., 2003). Furthermore, as discussed in Zardini et al. (2008), glutaric acid exhibits polymorphism (i.e., it exists as an $\alpha$ and a $\beta$ form), which influences its interactions with water vapor. Other possible explanations involve solvent from the atomized solution becoming trapped inside particles and escaping, causing an effective shrinking or collapse of hollow particles created by atomization (Rissman et al., 2007). It has also been suggested that partial evaporation of glutaric acid might account for the discrepancies (Cruz and Pandis, 1997). This was investigated further in this study. As seen in Fig. 10, glutaric acid particles with diameters in the range 40 to $110 \mathrm{~nm}$ apparently all activated at a larger critical supersaturation than predicted by Köhler theory. A possible explanation could be that glutaric acid evaporated from the surface of the particles after size selection in the DMA, but before exposure to supersaturation in the CCNC. In this case, the final diameter $\left(d_{\mathrm{fin}}\right)$ would be smaller than the diameter selected by the DMA $\left(d_{\mathrm{DMA}}\right)$. To test this hypothesis we corrected the data for evaporation inside the DMA and connecting tubing. The time between size selection in the DMA and the particles entering the CCNC was calculated as $t_{\mathrm{evap}}=0.5 t_{\mathrm{DMA}}+\mathrm{t}_{\text {tubing }}$ where $t_{\mathrm{DMA}}$ is the transit time through the DMA column (assuming that the size is selected halfway through the DMA column), and $t_{\text {tubing }}$ is the time the particles spent in tubing between the outlet of the DMA and the entrance to the CCNC. $t_{\text {tubing }}$ was estimated to be approximately $0.3 \mathrm{~s}$. In some experiments, an additional $2.7 \mathrm{~m}$ of tubing was inserted between the DMA and the CCNC to check for potential evaporation, increasing $t_{\text {tubing }}$ to $3 \mathrm{~s}$. Since the aerosol flow rate was not changed significantly between different experiments, the dependence on 


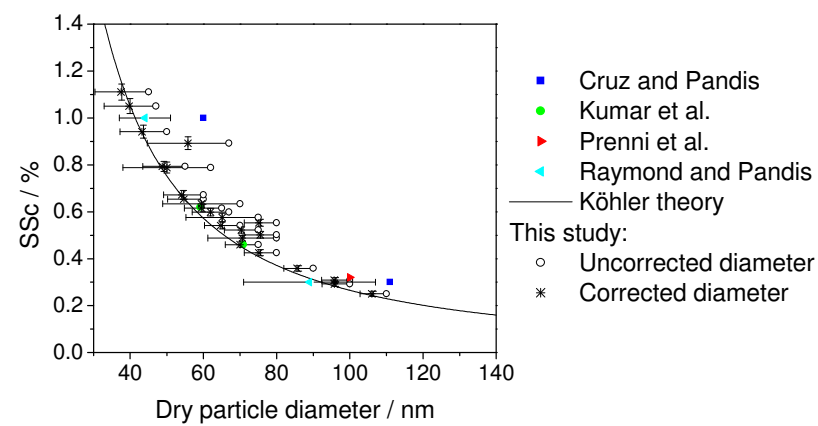

Fig. 10. The critical supersaturation of glutaric acid as a function of dry particle diameter (Cruz and Pandis, 1997; Prenni et al., 2001; Raymond and Pandis, 2002; Kumar et al., 2003). The experimental data is compared to Köhler theory (surface tension of pure water, dissociation calculated from the first acid constant).

the flow rate was negligible for $t_{\text {tubing. }} t_{\text {DMA }}$ was estimated to be in the range 1.0-1.2 s, depending on aerosol and sheath flows in the DMA. Times $\left(t_{\text {evap }}\right)$ were of the order of $1 \mathrm{~s}$ in experiments without the additional tubing and of the order of $4 \mathrm{~s}$ in experiments with additional tubing. The corrected dry particle diameters were determined using the vapor pressure of glutaric acid reported by Bilde et al. (2003).

Lower and upper limits for the dry particle size were estimated using the following evaporation times: $t_{\text {evap }}(\max )=t_{\mathrm{DMA}}+t_{\text {tubing }}$ (lower limit on particle size) and $t_{\text {evap }}(\min )=0$ corresponding to no evaporation (upper limit on particle size).

As can be seen from Fig. 10, agreement with Köhler theory to within the margin of error is attained when the corrected diameters and calculated uncertainties are included. No other effect is necessary to explain the initially observed deviations. We thus conclude that glutaric acid activates according to Köhler theory, using the surface tension of pure water.

\subsection{2- and 3-oxoglutaric acid}

Figure 11 shows examples of the evaporation of particles generated from atomization of oxo-acids in the laminar flowtube for similar number concentrations of particles. Clearly, particles of 2-oxoglutaric acid evaporate the most and 4oxopimelic acid the least, on a time scale of $250 \mathrm{~s}$. We obtain a vapor pressure of $3.2 \times 10^{-5} \mathrm{~Pa}$ and a surface free energy of $0.11 \mathrm{~J} \mathrm{~m}^{-2}$ for 2-oxoglutaric acid at $295 \mathrm{~K}$. This vapor pressure corresponds to a mixing ratio of $320 \mathrm{ppt}$ at saturation and places 2-oxoglutaric acid in the group of semivolatile molecules which can be found in the gas as well as the condensed phase in the atmosphere (Goldstein and Galbally, 2007).

Table 3 shows a sensitivity analysis for the inferred vapor pressure of 2-oxoglutaric acid. Lowering the accommodation coefficient to 0.5 changes the obtained vapor pres-

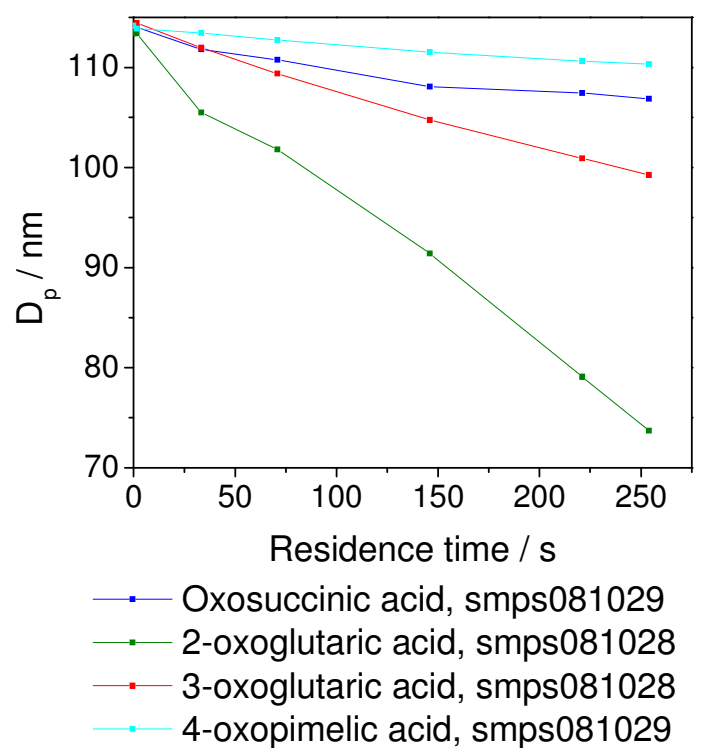

Fig. 11. Examples of evaporation rates of the four oxo-acids investigated in this study. The data points of each evaporation curve represent the particles size measured with a SMPS at the outlet of the first DMA at the entrance of the flow-tube, at four consecutive ports along the length of the flow-tube, and at the end of it. The connecting lines are to guide the eyes.

sure by $9 \%$. Varying the surface free energy between 0.012 and $0.212 \mathrm{~J} \mathrm{~m}^{-2}$ affects the vapor pressure by no more than $16 \%$. Allowing for a systematic error in the residence time by $\pm 10 \%$ changes the vapor pressure by less than $13 \%$. The table entry labeled "slope+" refers to a conservative error estimate on the measured diameters where the initial diameter is increased by $2 \mathrm{~nm}$, and the final diameter is decreased by $2 \mathrm{~nm}$ and vice versa for "slope-". It is an underlying assumption in our analysis that the vapor phase is depleted with respect to the evaporating species. To verify this assumption, we calculated the saturation ratio of the gas phase at the end of the flow-tube for the 2-oxoglutaric acid in Fig. 11. Based on the vapor pressure of $3.2 \times 10^{-5} \mathrm{~Pa}$, the saturation ratio of the gas phase with respect to 2-oxoglutaric acid is $\sim 10^{-6}$. In the sensitivity analysis we have conservatively assumed that the saturation ratio is 0.1 throughout the flow-tube and, even so, the vapor pressure is affected by only $13 \%$. Finally, we substitute the correction factor for the transition regime Eq. (7) with an alternative formulation given by Zhang et al. (1993) obtaining a 6\% difference.

The vapor pressure does not change by more than $16 \%$ for any of the perturbations shown in Table 3. Based on the sensitivity analysis we therefore estimate that the uncertainty on the vapor pressure is $16 \%$ or less. We estimate that potential systematic errors, impurities, and errors associated with the physical properties given in Table 3 could increase this uncertainty to $25 \%$ and we quote a vapor pressure for 2-oxoglutaric acid at $295 \mathrm{~K}$ of $(3.2 \pm 0.8) \times 10^{-5} \mathrm{~Pa}$. 
Table 3. Sensitivity analysis of the vapor pressure results for 2-oxoglutaric acid.

\begin{tabular}{lrrrr}
\hline Parameter & Pertubation & Base value & $d p / p \%$ & $p\left(10^{-5} \mathrm{~Pa}\right)$ \\
\hline$p$ & & $3.2 \times 10^{-5} \mathrm{~Pa}$ & & 3.2 \\
$T$ & $\pm 2 \mathrm{~K}$ & $296 \mathrm{~K}$ & $<3 \%$ & \\
$\alpha$ & -0.5 & 1 & $9 \%$ & 3.5 \\
$\sigma_{\text {s, air }}^{\mathrm{i}}$ & +0.1 & 0.112 & $-12.5 \%$ & 2.8 \\
$\sigma_{\text {s, air }}^{\text {r }}$ & -0.1 & 0.112 & $15.6 \%$ & 3.7 \\
Time & $10 \%$ & 0.187 & $12.5 \%$ & 3.6 \\
Time & $-10 \%$ & 0.187 & $-9.4 \%$ & 2.9 \\
Slope (+) & $\pm 2 \mathrm{~nm}$ & & $9 \%$ & 3.5 \\
Slope (-) & $\pm 2 \mathrm{~nm}$ & & $-9 \%$ & 2.6 \\
Saturation & 0.1 & 0 & $9 \%$ & 3.5 \\
Density & $\pm 10 \%$ & 1610 & $\pm 9 \%$ & 3.5 \\
Zhang et al. (1993) & & & $6 \%$ & 3.4 \\
Fuchs and Sutugin (1971) & & & - & 3.2 \\
\hline
\end{tabular}

Table 4. Properties derived from evaporation analysis and Köhler theory: vapor pressures $(p)$ and surface free energies $\left(\sigma_{\mathrm{s}, a i r}^{\mathrm{i}}\right)$ at the temperature $T$, critical supersaturation $\mathrm{SS}_{\mathrm{c}}$ for a dry particle with a diameter of $60 \mathrm{~nm}$, and the single hygroscopicity parameter, $\kappa$, averaged for all measurements.

\begin{tabular}{lrrrrr}
\hline Compound & $T$ & $\begin{array}{r}p \\
\mathrm{~Pa}_{\mathrm{s}, \text { air }}^{\mathrm{i}}\end{array}$ & $\begin{array}{r}\mathrm{SS}_{\mathrm{c}} \\
\mathrm{J} \mathrm{m}^{-2}\end{array}$ & $(D p=60 \mathrm{~nm}) \%$ & $\kappa$ \\
\hline 2-oxoglutaric acid & 295 & $3.2 \times 10^{-5}$ & 0.11 & $0.4845 \pm 0.012$ & $0.27 \pm 0.05$ \\
3-oxoglutaric acid products & 295 & $1.6 \times 10^{-5^{\mathrm{a}}}$ & $0.1^{\mathrm{a}}$ & $0.5591 \pm 0.02^{\mathrm{a}}$ & $0.19 \pm 0.05^{\mathrm{a}}$ \\
Oxosuccininc acid products & 294.3 & $1.0 \times 10^{-5^{\mathrm{a}}}$ & $0.181^{\mathrm{a}}$ & $0.4611 \pm 0.008^{\mathrm{a}}$ & $0.31 \pm 0.09^{\mathrm{a}}$ \\
4-oxopimelic acid & 294.5 & $3.0 \times 10^{-6}$ & 0.192 & $0.6438 \pm 0.016$ & $0.14 \pm 0.02$ \\
Pimelic acid & 296 & $5.1 \times 10^{-5^{\mathrm{b}}}$ & $0.08^{\mathrm{b}}$ & $0.6335 \pm 0.016$ & $0.15 \pm 0.04$ \\
Glutaric acid & 296 & $6.7 \times 10^{-4^{\mathrm{b}}}$ & $0.215^{\mathrm{b}}$ & $0.6158 \pm 0.018$ & $0.19 \pm 0.07$ \\
Succinic acid & 296 & $3.9 \times 10^{-5^{\mathrm{b}}}$ & $0.125^{\mathrm{b}}$ & $\mathrm{NA}$ & $\mathrm{NA}$ \\
\hline
\end{tabular}

a Vapor pressure and surface free energies are calculated assuming that decarboxylation has not occurred and that the particles are composed of the pure $\beta$-oxo-acid.

b From Bilde et al. (2003).

Comparison with the vapor pressure of glutaric acid from previous studies (e.g., $p=6.7 \times 10^{-4} \mathrm{~Pa}$ in Bilde et al., 2003) shows that the oxo-group lowers the vapor pressure significantly (about one order of magnitude).

Given that 3-oxoglutaric acid may undergo decarboxylation as described in Sect. 2.1 we do not know the exact chemical composition of the particles made from this acid. To be able to correct for evaporative losses in the tubing and DMA column in the CCN experiments we do however calculate a vapor pressure assuming that the evaporating molecules have the properties (molar weight, diffusivity etc.) of 3-oxoglutaric acid. Since we did not find a unique result for surface free energy with the minimization method described in Bilde and Pandis (2001), we assume that the surface free energy is similar to that of 2-oxoglutaric acid $\left(0.1 \mathrm{~J} \mathrm{~m}^{-2}\right)$. We thus obtain a vapor pressure of $p(3-$ oxoglutaric acid products $)=(1.6 \pm 0.4) \times 10^{5} \mathrm{~Pa}$ at $T=295 \mathrm{~K}$. Here we have adopted the uncertainty estimate of $25 \%$ from the above analysis of 2-oxoglutaric acid.

A related article has recently been published (Booth et al., 2010) where the authors use a Knudsen cell based method to extrapolate solid state vapor pressure at $T=298 \mathrm{~K}$. Relevant to our work, they report results for oxo-succinic, and 2- and 3 -oxoglutaric acids. However, only the vapor pressures of 2oxoglutaric acid can be compared, as 3-oxoglutaric and oxosuccinic acid undergo decarboxylation in aqueous mixtures (see previous Sections). They also observe a reduction (about a factor of 3) in vapor pressure of 2-oxoglutaric compared to glutaric acid. Yet, considering the experimental errors, they report a vapor pressure which is at best almost the double of ours. The disagreement may be related to the different temperatures of the experiments (about 4 degrees), but also 


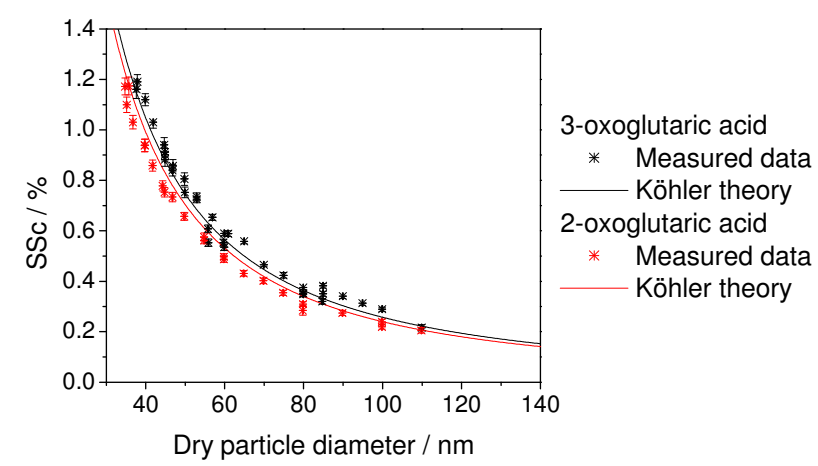

Fig. 12. The critical supersaturation of 2- and 3-oxoglutaric acid as a function of dry particle diameter. The experimental data is fitted to a Köhler curve (surface tension of water, dissociation calculated from acid constants).

differences in the two techniques should be explored in the future.

Figure 12 shows the measured critical supersaturations of 2- and 3-oxoglutaric acids versus dry particle diameter corrected for evaporative losses in the tubing as described in Sect. 4.1. Due to the low vapor pressures, the correction was negligible $(<1 \mathrm{~nm}$ in all cases).

The two acids have the same molar weight and similar acidity and density (see Table 1) and therefore Köhler theory predicts that $\mathrm{CCN}$ activation should be almost identical for the two isomers, as seen in Fig. 12 (black and red curves). However the CCN activity is clearly not the same as can also be seen from Fig. 12: 2-oxoglutaric acid ( $\alpha$-form) activates more readily than 3-oxoglutaric acid ( $\beta$-form), suggesting that the ratio between the molar mass and the product of the density and the van't Hoff factor is smaller for 2-oxoglutaric acid than for particles made from 3-oxoglutaric acid.

We believe that the difference is due to decarboxylation or aldol-reactions of 3-oxoglutaric acid for which the oxogroup is in the $\beta$-position. This conclusion is supported by the HPLC/ESI $(-/+)$-MS measurements of the composition of a bulk aqueous solution of 2-oxoglutaric acid and 3oxoglutaric acid, shown in Fig. 13. The compounds exhibit different behaviors. No evidence of decarboxylation can be seen in the case of 2-oxoglutaric acid (Fig. 13a). The signal of the decarboxylated species has the same retention time as the deprotonated molecular ion. This is a clear sign that the decarboxylation happens during the ionization step, a common feature of the ESI-spectra of organic acids (Grossert et al., 2005). In contrast, 3-oxoglutaric acid shows clear evidence of decarboxylation. The extracted ion chromatogram again shows the signal of the decarboxylated and the deprotonated species, however, with a clear shift in the retention times. This behavior can only be explained by a decarboxylation in bulk aqueous solution before the analysis.
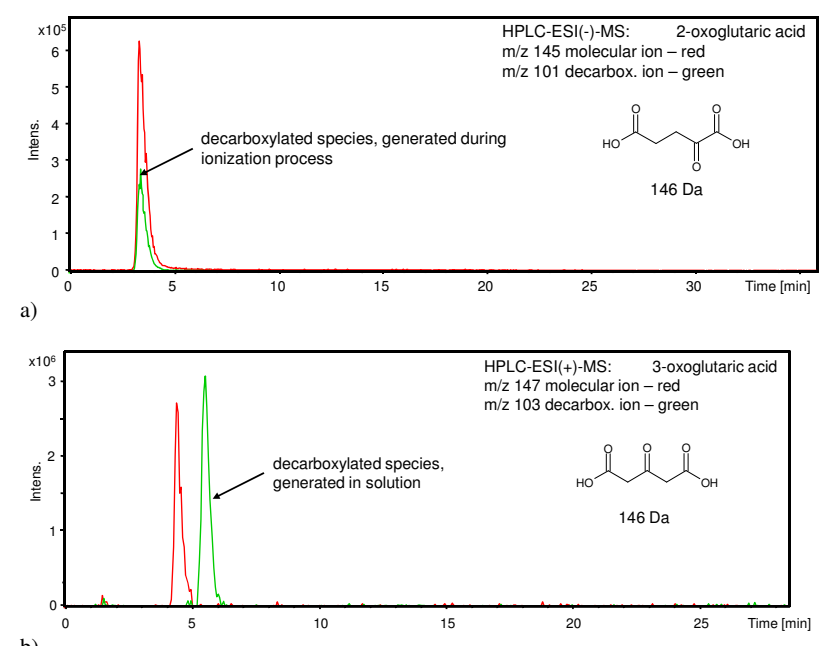

b)

Fig. 13. HPLC-ESI(-/+)-MS extracted ion chromatograms of 2-oxoglutaric acid (a) and 3-oxoglutaric acid (b). In the chromatogram of 2-oxoglutaric acid, the signals from the product of decarboxylation and from the molecular ion are coincident (retention time approximately $4.5 \mathrm{~min}$ ), indicating that the decarboxylation occurred during the ionization process. In the chromatogram of 3-oxoglutaric acid the peak from the decarboxylated species appears at a different retention time $(5.5 \mathrm{~min})$, which shows that decarboxylation occurred prior to the ionization. Note that due to sensitivity reasons (a) was measured in the negative ion mode whereas (b) was in the positive ion mode.

$\kappa$ values were calculated for each set of measured dry particle diameters and critical supersaturations. The average $\kappa$ value for 2-oxoglutaric acid is $0.27 \pm 0.05$. For comparison the $\kappa$ value for glutaric acid is $0.19 \pm 0.07$ and we see that the oxo-group increases $\mathrm{CCN}$ activity. The $\kappa$ value for particles made from 3-oxoglutaric acid was $0.19 \pm 0.05$; a significantly lower value than for 2-oxoglutaric acid. For comparison ammonium sulfate has a $\kappa$ value of 0.61 (Petters and Kreidenweis, 2007).

\subsection{Pimelic and 4-oxopimelic acid}

Following the same approach described above for 2oxoglutaric acid and adopting the error estimate of $25 \%$, we obtain a vapor pressure of 4-oxopimelic acid of $p=(3.0 \pm 0.8) \times 10^{-6} \mathrm{~Pa}$ and a surface free energy of $0.19 \mathrm{~J} \mathrm{~m}^{-2}$ at $294.48 \mathrm{~K}$. For comparison the vapor pressure of pimelic acid at this temperature is $(5.4 \pm 2.7) \times 10^{-5} \mathrm{~Pa}$ (Bilde et al., 2003); the oxo-group lowers the vapor pressure of the parent dicarboxylic acid by an order of magnitude as it also did for 2-oxoglutaric acid.

The vapor pressure of 4-oxopimelic acid corresponds to a mixing ratio of $30 \mathrm{ppt}$ at saturation and places the compound among the group of molecules which are mainly found in the condensed phase in the atmosphere (Goldstein and Galbally, 2007). 


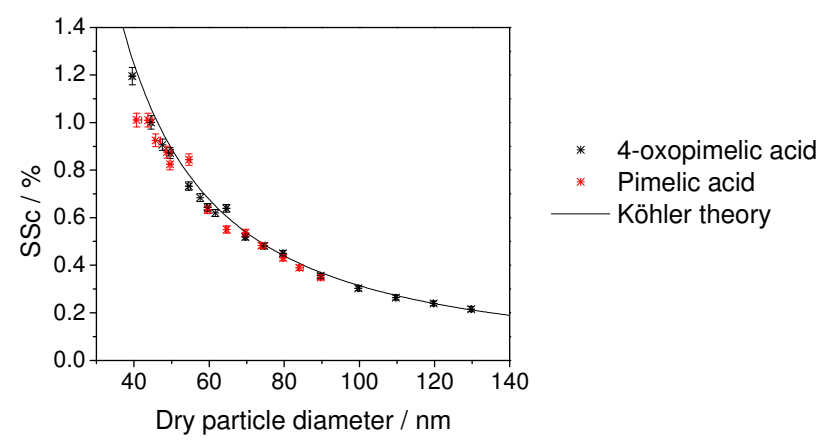

Fig. 14. The critical supersaturation of pimelic acid and 4oxopimelic acid as a function of dry particle diameter. The experimental data are compared to a Köhler curve (surface tension of water, no dissociation).

Using the same experimental system as in this work, it has previously been shown that the solid state vapor pressure of dicarboxylic acids alternates with the number of carbon atoms and that the acids with an odd number of carbon atoms have the highest vapor pressures, probably due to a less stable solid state structure than the even acids (Bilde et al., 2003). It has also previously been shown that the vapor pressure of the even acids may increase when the stable structure is perturbed by a methyl group whereas addition of one or two methyl groups $(\Delta M=14-28 \mathrm{~g} / \mathrm{mol})$ to the carbon skeleton of the odd carbon number dicarboxylic acid has a small influence on vapor pressure at ambient conditions (Mønster et al., 2004). It is thus notable that the oxo-group ( $\Delta M=16 \mathrm{~g} / \mathrm{mol}$ ) has such a strong decreasing effect on vapor pressure for pimelic acid which has an odd number of carbon atoms.

Figure 14 shows the measured critical supersaturation of pimelic and 4-oxopimelic acids versus dry particle diameter corrected for evaporation losses, as described in Sect. 4.1. The vapor pressures of pimelic and 4-oxopimelic acids are so low that evaporation in the DMA and connecting tubing is negligible $(<1.5 \mathrm{~nm})$. Although pimelic and 4-oxopimenlic acid have different molar weights and densities, the ratio between the molar weight and density is almost equal. Both compounds are weak acids, and dissociation can be neglected. The van't Hoff factor of both compounds is thus assumed to be 1 . Therefore, Köhler theory predicts that the two compounds will activate at approximately the same supersaturation, see Fig. 14. This is in good agreement with experimental data. The $\kappa$ values of pimelic and oxo-pimelic acid are almost identical: $0.15 \pm 0.04$ and $0.14 \pm 0.02$, respectively. This is unlike the glutaric acids where an oxo-group had a significant effect on $\mathrm{CCN}$ activity

LC/MS analysis of 4-oxopimelic acid shows no signs of decomposition. This is displayed in Fig. 15. A clear signal at $8.3 \mathrm{~min}$ represents deprotonated ions of the oxocarboxylic acid (red signal), whereas only a small fraction decarboxylates during the ionization step (green signal).

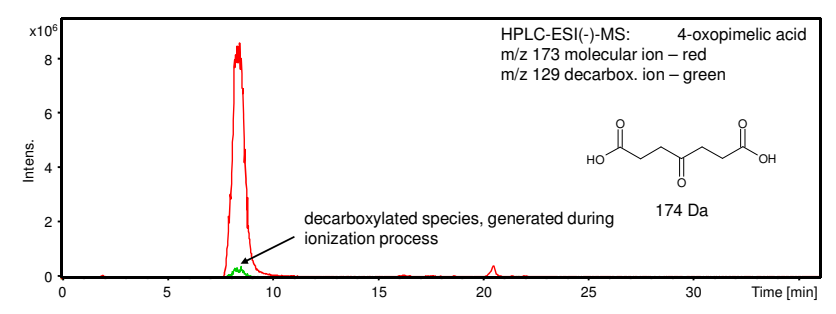

Fig. 15. HPLC-ESI(-)-MS extracted ion chromatograms of 4oxopimelic acid. The signals from the product of decarboxylation and from the molecular ion are coincident (retention time approximately $8.3 \mathrm{~min}$ ), indicating that the decarboxylation occurred during the ionization process.

\subsection{Oxosuccinic acid}

Like 3-oxoglutaric acid, oxosuccinic acid may have undergone chemical reaction before the evaporation rate and $\mathrm{CCN}$ activity were measured. The final products of these reactions - and therefore the composition of the particles are unknown. Nevertheless, we calculate the vapor pressure, assuming that the evaporating molecules have the properties of oxosuccinic acid, and obtain $p$ (oxosuccinic acid products $)=(1.0 \pm 0.3) \times 10^{-5} \mathrm{~Pa}$ and a surface free energy of $0.181 \mathrm{~J} \mathrm{~m}^{-2}$ at $294.27 \mathrm{~K}$.

Figure 16 shows critical supersaturations versus dry particle diameters for particles generated from oxosuccinic acid. The critical supersaturations are in reasonable agreement with predictions from Köhler theory calculated using the molar mass and density of oxosuccinic acid and a van't Hoff factor based on the first acid constant of oxosuccinic acid. The dry particle diameters shown in Fig. 16 have been corrected for evaporative losses in the tubing using the vapor pressure given above. Corrections were negligble $(<0.2 \mathrm{~nm})$.

The LC/MS run shown in Fig. 17 demonstrates that oxosuccinic acid undergoes decarboxylation in bulk aqueous solution. As already mentioned for 3-oxoglutaric acid a retention time shift between the molecular ion $(\mathrm{m} / \mathrm{z}, 131$, red signal) and the decarboxylated species ( $\mathrm{m} / \mathrm{z} 87$, green signal) is the consequence of a decarboxylation process in solution before the LC/MS measurement.

One of the possible products of the chemical reactions of oxosuccinic acid in aqueous solution is pyruvic acid. Pyruvic acid has a molar mass of $88.06 \mathrm{~mol} / \mathrm{g}$, a density of $1.2650 \mathrm{~g} / \mathrm{ml}$ (Yaws, 2005) and a pKa of 2.49 (Pedersen, 1952). Assuming that the aerosol particles were composed solely of pyruvic acid and using these physical properties, critical supersaturations were calculated using Köhler theory as a function of dry particle size (red line in Fig. 16). The calculated critical supersaturations for oxosuccinic acid and pyruvic acids are almost identical, and the measured data agrees quite well with both of the theoretical lines. 


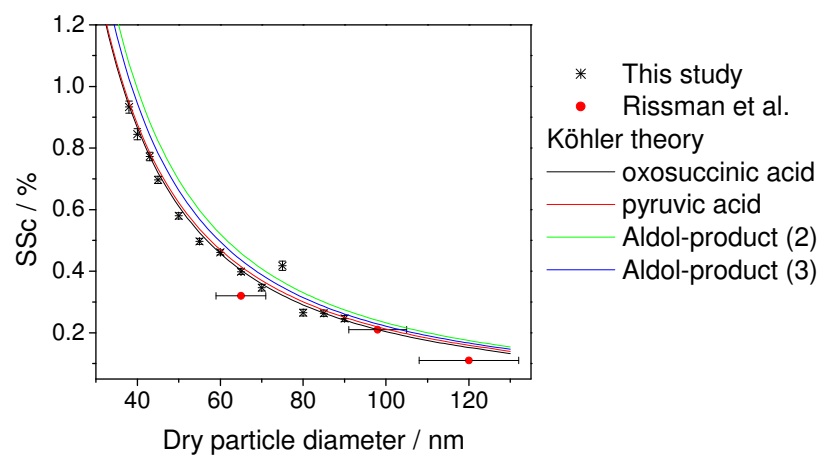

Fig. 16. The critical supersaturation of oxosuccinic acid as a function of dry particle diameter. Experimental data are compared to Köhler theory (dissociation based on the first acid constant, surface tension of water). Four Köhler curves are shown, using the following data: black: pure oxosuccinic acid. Red: pyruvic acid, $M=88.06 \mathrm{~g} / \mathrm{mol} ; \rho=1.250 \mathrm{~g} / \mathrm{ml} ; \mathrm{pKa}=2.49$. Green: citroylformic acid; $M=220.13 \mathrm{~g} / \mathrm{mol} ; \rho=1.795 \mathrm{~g} / \mathrm{ml}, \mathrm{pKa}=1$. Blue: 4-hydroxy-4-mehtyl-2-ketoglutaric acid; $M=176.12 \mathrm{~g} / \mathrm{mol}$, $\rho=1.579 \mathrm{~g} / \mathrm{ml}, \mathrm{pKa}=1$.

Other possible products from the reactions of oxosuccinic acid are citroylformic acid $(M=220.13 \mathrm{~g} / \mathrm{mol}$, $\left.\rho=1.795 \pm 0.06 \mathrm{~g} / \mathrm{cm}^{3}\right)$ and 4-hydroxy-4-methyl-2oxoglutaric acid $\left(M=176.12 \mathrm{~g} / \mathrm{mol}, \rho=1.579 \pm 0.06 \mathrm{~g} / \mathrm{cm}^{3}\right)$, see Fig. 4 and Fig. 5. No information about physical properties of these compounds was found in the literature. Instead, densities were modeled with $\mathrm{ACD} / \mathrm{ChemSketch}$, Version 4.01, and for both compounds $\mathrm{pKa}=1$ was used to estimate the degree of dissociation. Critical supersaturations calculated assuming the particles to be either citroylformic acid or 4-hydoxy-4-methyl-2-oxoglutaric acid are higher than the critical supersaturations calculated using Köhler theory for oxosuccinic acid and pyruvic acid and also higher than the measured values. If a larger (and probably more realistic) pKa value had been used, the predicted critical supersaturations for the aldol products would be even higher. This indicates that these compounds are probably not present in significant amounts in the studied aerosols.

In this study, aerosol particles were prepared from an aqueous solution using an atomizer. If another solvent, e.g. methanol, had been used, this would have had an effect on equilibrium between the keto-, enol-, and hydrated forms (Kumler et al., 1962). Since only the keto-form can participate in decarboxylation, another choice of solvent would probably lead to different reaction rates and concentrations of the various possible products. This is important to be aware of in future $\mathrm{CCN}$ experiments.

Rissman et al. (2007) studied CCN activation of particles made by dissolving oxosuccinic acid (oxalacetic acid) in water and in methanol. Within experimental uncertainties they did not observe solvent-dependent CCN ability for supersaturations of $0.11 \%, 0.21 \%$ and $0.32 \%$. For comparison, the

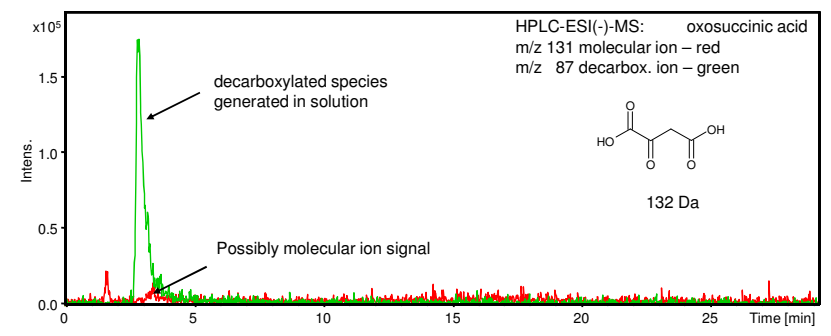

Fig. 17. HPLC-ESI(-)-MS extracted ion chromatograms of oxosuccinic acid. A clear shift in retention time is observed between the molecular ion and the decarboxylated species, indicating that oxosuccinic acid spontaneously decarboxylated in aqueous solution prior to analysis.

data by Rissman et al. (2007), using water as the solvent, is shown in Fig. 15. According to Rissman et al. (2007) the particles activate slightly more easily than observed in this study. This could be due to differences in experimental conditions which alter the degree of decomposition of the $\beta$-oxo-acid: temperature, concentration in the atomized solution, timescale of experiment, and the chemical composition of any impurities.

The average $\kappa$ value for oxosuccinic acid (products) obtained from our measurements is $0.31 \pm 0.09$ which is in the high end, but still comparable to $\kappa$ values of other water soluble organic molecules studied (Petters et al., 2009).

\section{Conclusion and perspectives}

We have investigated the evaporation and cloud forming ability of a series of oxo-dicarboxylic acids: oxosuccinic acid, 2oxoglutaric acid, 3-oxoglutaric acid, and 4-oxopimelic acid, all of which have been detected in the atmosphere or are considered surrogate standards for atmospherically relevant organic compounds. Oxo-acids with the oxo-group in $\beta$ position can undergo decarboxylation in aqueous solutions and our results suggest that this happens for the two studied $\beta$-oxo-acids: oxosuccinic acid and 3-oxoglutaric acid. This might explain why, to our knowledge, they have not been reported to exist in the condensed phase in the atmosphere.

The vapor pressures of 2-oxoglutaric acid and 4oxopimelic acid correspond to mixing ratios of $320 \mathrm{ppt}$ and $30 \mathrm{ppt}$, respectively, at saturation and $1 \mathrm{~atm}$ total pressure which places 2-oxoglutaric acid in the group of semi-volatile compounds which can be found in the gas as well as the condensed phase in the atmosphere, and 4-oxopimelic acid among the molecules which are mainly found in the condensed phase in the atmosphere (Goldstein and Galbally, 2007).

It is interesting to compare the vapor pressures with the corresponding values for the parent straight chain dicarboxylic acids. Clearly, the oxo-group has a strong effect on 
the vapor pressure and lowers it by one order of magnitude, suggesting that multifunctional acids should be further investigated for their potential role in nucleation and growth of atmospheric nuclei.

Oxosuccinic acid and 3-oxoglutaric acid have probably undergone decarboxylation in the atomizer bottle in our experiments, and therefore we do not know the exact chemical composition of the particles we have studied. It is however likely that this will also happen in atmospheric aerosols containing enough water. Assuming that the evaporating molecules have the same physico-chemical properties as their parent dicarboxylic acids, our best estimate is that the vapor pressure of the products are of the order of $10^{-5} \mathrm{~Pa}$.

We have investigated the ability of glutaric acid, pimelic acid, and the four oxo-acids to act as cloud condensation nuclei. Glutaric acid has previously been studied and discussed in the literature, and discrepancies with Köhler theory have been reported. We find that for our experimental setup it is necessary to correct for evaporation of the particles in the DMA column and connecting tubing (even on a time scale of seconds), and that glutaric acid particles activate according to Köhler theory using a van't Hoff factor of 1 .

The $\alpha$-oxo-acids (2-oxoglutaric acid and 4-oxopimelic) can both act as cloud condensation nuclei with $\kappa$ values of 0.27 and 0.14 , respectively. The $\kappa$ values derived for particles made from 3-oxoglutaric acid and oxosuccinic acid are 0.19 and 0.31 respectively. This is slightly less CCN active than ammonium sulfate $(\kappa=0.61)$, but comparable to many other organic molecules with a similar number of carbon atoms. Overall, the CCN activity of particles made from oxo-dicarboxylic acids is similar to or higher than the corresponding straight chain dicarboxylic acids.

\section{Supplementary material related to this article is available online at: http://www.atmos-chem-phys.net/10/5873/2010/ acp-10-5873-2010-supplement.pdf.}

Acknowledgements. We acknowledge EUCAARI (European Integrated project on Aerosol Cloud Climate and Air Quality interactions) No. 036833-2, the Danish Natural Research Council, Carlsbergs Mindelegat for Brygger J. C. Jacobsen and EUROCHAMP 2.

Edited by: M. Ammann

\section{References}

Bilde, M. and Pandis, S. N.: Evaporation rates and vapor pressures of individual aerosol species formed in the atmospheric oxidation of $\alpha$ - and $\beta$-pinene, Environ. Sci. Technol., 35, 3344-3349, doi:10.1021/es001946b, 2001.

Bilde, M., Svenningsson, B., Mønster, J., and Rosenørn, T.: Evenodd alternation of evaporation rates and vapor pressures of C3-
C9 dicarboxylic acid aerosols, Environ. Sci. Technol., 37, 13711378, doi:10.1021/es0201810, 2003.

Bilde, M. and Svenningsson, B.: CCN activation of slightly soluble organics: the importance of small amounts of inorganic salt and particle phase, Tellus B, 56, 128-134, doi:10.1111/j.16000889.2004.00090.x, 2004.

Bird, R. B., Steward, W. E., and Lightfoot, E. N.: Transport phenomena, John Wiley \& Sons, New York, 1960.

Booth, A. M., Markus, T., McFiggans, G., Percival, C. J., Mcgillen, M. R., and Topping, D. O.: Design and construction of a simple Knudsen Effusion Mass Spectrometer (KEMS) system for vapour pressure measurements of low volatility organics, Atmos. Meas. Tech., 2, 355-361, doi:10.5194/amt-2-355-2009, 2009.

Booth, A. M., Barley, M. H., Topping, D. O., McFiggans, G., Garforth, A., and Percival, C. J.: Solid state and sub-cooled liquid vapour pressures of substituted dicarboxylic acids using Knudsen Effusion Mass Spectrometry (KEMS) and Differential Scanning Calorimetry, Atmos. Chem. Phys., 10, 4879-4892, doi:10.5194/acp-10-4879-2010, 2010.

Buldain, G., de los Santos, C., and Frydman, B.: Carbon-13 nuclear magnetic resonance spectra of the hydrate, keto and enol forms of oxalacetic acid, Magn. Reson Chem., 23, 478-481, doi:10.1002/mrc.1260230615, 1985.

Cappa, C. D., Lovejoy, E. R., and Ravishankara, A. R.: Determination of evaporation rates and vapor pressures of very low volatility compounds: A study of the C4-C10 and C12 dicarboxylic acids, J. Phys. Chem. A., 111, 3099-3109, doi:10.1021/jp068686q, 2007.

Chattopadhyay, S. and Ziemann, P. J.: Vapor pressures of substituted and unsubstituted monocarboxylic and dicarboxylic acids measured using an improved thermal desorption particle beam mass spectrometry method, Aerosol Sci. Techol., 39, 1085-1100, doi:10.1080/02786820500421547, 2005.

Cruz, C. N. and Pandis, S. N.: A study of the ability of pure secondary organic aerosol to act as cloud condensation nuclei, Atmos. Environ., 31, 2205-2214, doi:10.1016/S13522310(97)00054-X, 1997.

Davis, E. J. and Ray, A. K.: Submicron droplet evaporation in the continuum and non-continuum regimes, J. Aerosol Sci., 9, 411422, doi:10.1016/0021-8502(78)90003-4, 1978

Dinar, E., Taraniuk, I., Graber, E. R., Katsman, S., Moise, T., Anttila, T., Mentel, T. F., and Rudich, Y.: Cloud Condensation Nuclei properties of model and atmospheric HULIS, Atmos. Chem. Phys., 6, 2465-2482, doi:10.5194/acp-6-2465-2006, 2006.

Dinar, E., Taraniuk, I., Graber, E. R., Anttila, T., Mentel, T. F., and Rudich, Y.: Hygroscopic growth of atmospheric and model humic-like substances, J. Geophys. Res-Atmos, 112, D05211, doi:10.1029/2006jd007442, 2007.

Elias, T., Haeffelin, M., Drobinski, P., Gomes, L., Rangognio, J., Bergot, T., Chazette, P., Raut, J. C., and Colomb, M.: Particulate contribution to extinction of visible radiation: Pollution, haze, and fog, Atmos. Res., 92, 443-454, doi:10.1016/j.atmosres.2009.01.006, 2009.

Emly, M. and Leussing, D. L.: Dehydration and enolization rates of oxalacetate - catalysis by tertiary amines, J. Am. Chem. Soc., 103, 628-634, doi:10.1021/ja00393a022, 1981.

Fuchs, N. A., Sutugin, A. G., Hidy, G. N., and Brock, J. R.: Topics in current aerosol research, Pergamon Press, New York, 1971. 
Gao, S., Keywood, M., Ng, N. L., Surratt, J. D., Varutbangkul, V., Bahreini, R., Flagan, R. C., and Seinfeld, J. H.: Lowmolecular-weight and oligomeric components in secondary organic aerosol from the ozonolysis of cycloalkenes and $\alpha$-pinene, J. Phys. Chem. A., 108, 10147-10164, doi:10.1021/jp047466e, 2004.

Goldstein, A. H. and Galbally, I. E.: Known and unexplored organic constituents in the Earth's atmosphere, Environ. Sci. Technol., 41, 1514-1521, doi:10.1021/es072476p, 2007.

Graber, E. R. and Rudich, Y.: Atmospheric HULIS: How humiclike are they? A comprehensive and critical review, Atmos. Chem. Phys., 6, 729-753, doi:10.5194/acp-6-729-2006, 2006.

Grossert, J. S., Fancy, P. D., and White, R. L.: Fragmentation pathways of negative ions produced by electrospray ionization of acyclic dicarboxylic acids and derivatives, Can. J. Chem.-Rev. Can. Chim., 83, 1878-1890, doi:10.1139/v05-214, 2005.

Hartz, K. E. H., Tischuk, J. E., Chan, M. N., Chan, C. K., Donahue, N. M., and Pandis, S. N.: Cloud condensation nuclei activation of limited solubility organic aerosol, Atmos. Environ., 40, 605617, doi:10.1016/j.atmosenv.2005.09.076, 2006.

Guzman, M. I. and Martin, S. T. Oxaloacetate-to-malate conversion by mineral photoelectrochemistry: implications for the viability of the reductive tricarboxylic acid cycle in prebiotic chemistry, Int. J. Astrobiol., 7, 271-278, doi:10.1017/S1473350408004291, 2008.

Hay, R. W. and Bond, M. A.: Kinetics of decarboxylation of acetoacetic acid, Aust. J. Chem., 20, 1823-1828, doi:10.1071/CH9671823, 1967.

Henning, S., Rosenrn, T., D’Anna, B., Gola, A. A., Svenningsson, B., and Bilde, M.: Cloud droplet activation and surface tension of mixtures of slightly soluble organics and inorganic salt, Atmos. Chem. Phys., 5, 575-582, doi:10.5194/acp-5-575-2005, 2005.

Hori, M., Ohta, S., Murao, N., and Yamagata, S.: Activation capability of water soluble organic substances as CCN, J. Aerosol Sci., 34, 419-448, doi:10.1016/S0021-8502(02)00190-8 2003.

IPCC: Climate Change 2007: The Physical Science Basis. Contribution of Working Group I to the Fourth Assessment Report of the Intergovernmental Panel on Climate Change. Cambridge University Press, Cambridge, UK, 2007.

Kanakidou, M., Seinfeld, J. H., Pandis, S. N., Barnes, I., Dentener, F. J., Facchini, M. C., Van Dingenen, R., Ervens, B., Nenes, A., Nielsen, C. J., Swietlicki, E., Putaud, J. P., Balkanski, Y., Fuzzi, S., Horth, J., Moortgat, G. K., Winterhalter, R., Myhre, C. E. L., Tsigaridis, K., Vignati, E., Stephanou, E. G., and Wilson, J.: Organic aerosol and global climate modelling: a review, Atmos. Chem. Phys., 5, 1053-1123, doi:10.5194/acp-5-1053-2005, 2005.

Kawamura, K. and Kaplan, I. R.: Motor exhaust emissions as a primary source for dicarboxylic acids in Los Angeles ambient air, Environ. Sci. Technol., 21, 105-110, doi:10.1021/es00155a014, 1987.

Kawamura, K., Kasukabe, H., Yasui, O., and Barrie, L. A.: Production of dicarboxylic acids in the arctic atmosphere at polar sunrise, Geophys. Res. Lett., 22, 1253-1256, doi:10.1029/95GL00880, 1995.

Kawamura, K., Seméré, R., Imai, Y., Fujii, Y., and Hayashi, M.: Water soluble dicarboxylic acids and related compounds in Antarctic aerosols, J. Geophys. Res-Atmos, 101, 18721-18728, doi:10.1029/96JD01541, 1996.
Kawamura, K. and Sakaguchi, F.: Molecular distribution of water soluble dicarboxylic acids in marine aerosols over the pacific ocean including tropics, J. Geophys. Res., 104, 3501-3509, doi:10.1029/1998JD100041, 1999.

Köhler, H.: The nucleus in and the growth of hygroscopic droplets, T. Faraday Soc., 32, 1152-1161, doi:10.1039/TF9363201152, 1936.

Kokesh, F. C.: Determination by proton nuclear magneticresonance of the enol, hydrate, and keto forms of oxaloacetic acid and its anions, J. Org. Chem., 41, 3593-3599, doi:10.1021/jo00884a025, 1976.

Koponen, I. K., Riipinen, I., Hienola, A., Kulmala, M., and Bilde, M.: Thermodynamic properties of malonic, succinic, and glutaric acids: Evaporation rates and saturation vapor pressures, Environ. Sci. Technol., 41, 3926-3933, doi:10.1021/es0611240, 2007.

Kornberg, A., Ochoa, S., and Mehler, A. H.: Spectrophotometric studies on the decarboxylation of $\beta$-keto acids, J. Biol. Chem., 174, 159-172, 1948.

Kosicki, G. W. and Lipvac, S. N.: The pH and pD dependence of the spontaneous and magnesium-ion-catalyzed decarboxylation of oxalacetic acid, Can. J. Chem., 42, 403-415, doi:10.1139/v64057, 1964.

Kosicki, G. W., Lipovac, S. N., and Annett, R. G.: Lithium chloride catalyzed decarboxylation of oxalacetic acid in ethanol, Can. J. Chem., 42, 2806-2810, doi:10.1139/v64-057, 1964.

Krebs, H. A.: The effects of inorganic salts on the ketone decomposition of oxaloacetic acid, Biochem. J., 36, 303-305, 1942.

Kristensson, A., Rosenørn, T., and Bilde, M.: Cloud droplet activation of amino acid aerosol particles, J. Phys. Chem. A., 114, 379-386, doi:10.1021/jp9055329, 2010.

Kulmala, M. and Wagner, P. E.: Mass accommodation and uptake coefficients - a quantitative comparison, J. Aerosol Sci., 32, 833841, doi:10.1016/S0021-8502(00)00116-6, 2001.

Pradeep Kumar, P., Broekhuizen, K., and Abbatt, J. P. D.: Organic acids as cloud condensation nuclei: Laboratory studies of highly soluble and insoluble species, Atmos. Chem. Phys., 3, 509-520, doi:10.5194/acp-3-509-2003, 2003.

Kumler, W. D., Kun, E., and Shoolery, J. N.: The enolization of oxaloacetic acid, diethyl oxaloacetate, and diethyl fluorooxaloacetate as determined by NMR analyses, J. Org. Chem., 27, 11651167, doi:10.1021/jo01051a010, 1962.

Laden, F., Schwartz, J., Speizer, F. E., and Dockery, D. W.: Reduction in fine particulate air pollution and mortality - Extended follow-up of the Harvard six cities study, Am. J. Resp. Crit. Care, 173, 667-672, doi:10.1164/rccm.200503-443OC, 2006.

Larson, D. W. and Lister, M. W.: Catalytic decomposition of acetonedicarboxylic acid, Can. J. Chemistry, 46, 823-832, doi:10.1139/v68-143, 1968.

Lide, D. R.: CRC Handbook of Chemistry and Physics, 85th edition., CRC Press, Boce Raton, 2004.

Liu, B. Y. H. and Bademosi, F.: Diffusion charging of Knudsen Aerosols, PTL publication no. 156, Particle Technology Laboratory, University of Minnesota, 1971.

Loewus, F. A., Tchen, T. T., and Vennesland, B.: The enzymatic transfer of hydrogen. III. The reaction catalyzed by malic dehydrogenase, J. Biol. Chem., 212, 787-800, 1955.

Low, R. D. H.: A theoretical study of nineteen condensation nuclei, Journal de Recherches Atmosphériques, 4, 65-78, 1969. 
Lyderson, A. L.: Estimation of Critical Properties of Organic Compounds by the Method of Group Contributions; Engineering Experiment Station Report 3; University of Wisconsin: Madison, WI, 1955.

McMurry, J.: Fundamentals of organic chemistry, Thomson Brooks/Cole, California, 2003.

Mønster, J., Rosenørn, T., Svenningsson, B., and Bilde, M.: Evaporation of methyl- and dimethyl-substituted malonic, succinic, glutaric and adipic acid particles at ambient temperatures, J. Aerosol Sci., 35, 1453-1465, doi:10.1016/j.jaerosci.2004.07.004, 2004.

Pedersen, K. J.: The dissociation constants of pyruvic and oxaloacetic acid, Acta Chem. Scand., 6, 243-256, 1952.

Petters, M. D. and Kreidenweis, S. M.: A single parameter representation of hygroscopic growth and cloud condensation nucleus activity, Atmos. Chem. Phys., 7, 1961-1971, doi:10.5194/acp-71961-2007, 2007.

Petters, M. D. , Kreidenweis, S. M., Prenni, A. J., Sullivan, R. C., Carrico, C. M., Koehler, K. A., and P. J. Ziemann: Role of molecular size in cloud droplet activation, Geophys. Res. Lett., 36, L22801, doi:10.1029/2009GL040131, 2009.

Pogson, C. I. and Wolfe, R. G.: Oxaloacetic acid. Tautomeric and hydrated forms in solution, Biochem. Biophys. Res. Co., 46, 1048-1054, 1972.

Prenni, A. J., DeMott, P. J., Kreidenweis, S. M., Sherman, D. E., Russell, L. M., and Ming, Y.: The effects of low molecular weight dicarboxylic acids on cloud formation, J. Phys. Chem. A., 105, 11240-11248, doi:10.1021/jp012427d, 2001.

Prisle, N. L., Raatikainen, T., Sorjamaa, R., Svenningsson, B., Laaksonen, A., and Bilde, M.: Surfactant partitioning in cloud droplet activation: a study of C8, C10, C12 and C14 normal fatty acid sodium salts, Tellus B, 60, 416-431, doi:10.1111/j.16000889.2008.00352.x, 2008.

Prue, J. E.: The kinetics of the metal-ion catalysed decarboxylation of acetonedicarboxylic acid, J. Chem. Soc., 2331-2338, doi:10.1039/JR9520002331, 1952.

Rader, D. J., McMurry, P. H., and Smith, S.: Evaporation rates of monodisperse organic aerosols 0.02- to 0.2- $\mu \mathrm{m}$-diameter range. Aerosol Sci. Tech.. 6, 247-260, doi:10.1080/02786828708959137, 1987.

Raghavan, N. V. and Leussing, D. L.: Kinetic study of the copper(II)-catalyzed enolization, ketonization, and decarboxylation of oxaloacetate, J. Am. Chem. Soc., 98, 723-730, doi:10.1021/ja00419a014, 1976.

Raymond, T. M. and Pandis, S. N.: Cloud activation of singlecomponent organic aerosol particles, J. Geophys. Res., 107, 161-16-8, doi:10.1029/2002JD002159, 2002.

Riipinen, I., Koponen, I. K., Frank, G. P., Hyvaerinen, A. P., Vanhanen, J., Lihavainen, H., Lehtinen, K. E. J., Bilde, M., and Kulmala, M.: Adipic and malonic acid aqueous solutions: Surface tensions and saturation vapor pressures, J. Phys. Chem. A., 111, 12995-13002, doi:10.1021/jp073731v, 2007.

Rissman, T. A., Varutbangkul, V., Surratt, J. D., Topping, D. O., McFiggans, G., Flagan, R. C., and Seinfeld, J. H.: Cloud condensation nucleus $(\mathrm{CCN})$ behavior of organic aerosol particles generated by atomization of water and methanol solutions, Atmos. Chem. Phys., 7, 2949-2971, doi:10.5194/acp-7-2949-2007, 2007.

Rogge, W. F., Mazurek, M. A., Hildemann, L. M., and Cass, G.
R.: Quantification of urban organic aerosols at a molecular level: Identification, abundance and seasonal variation, Atmos. Environ., 27, 1309-1330, doi:10.1016/0960-1686(93)90257-Y, 1993.

Sakaguchi, F. and Kawamura, K.: Identification of 4oxoheptanedioic acid in the marine atmosphere by capillary gas chromatography-mass spectrometry, J. Chromatogr. A, 687, 315-321, doi:10.1016/0021-9673(94)00925-2, 1994.

Saxena, P. and Hildemann, L. M.: Water-soluble organics in atmospheric particles: A critical review of the literature and application of thermodynamics to identify candidate compounds, J. Atmos. Chem., 24, 57-109, 1996.

Seinfeld, J. H. and Pandis, S. N.: Atmospheric chemistry and physics: From air pollution to climate change. Wiley Interscience Publication, John Wiley and Sons, New York, 1998.

Sjogren, S., Gysel, M., Weingartner, E., Baltensperger, U., Cubison, M. J., Coe, H., Zardini, A. A., Marcolli, C., Krieger, U. K., and Peter, T.: Hygroscopic growth and water uptake kinetics of two-phase aerosol particles consisting of ammonium sulfate, adipic and humic acid mixtures, J. Aerosol Sci., 38, 157-171, doi:10.1016/j.jaerosci.2006.11.005, 2007.

Steinberger, R. and Westheimer, F. H.: Metal ion-catalyzed decarboxylation: A model for an enzyme system, J. Am. Chem. Soc., 73, 429-435, doi:10.1021/ja01145a139, 1951.

Svenningsson, B., Rissler, J., Swietlicki, E., Mircea, M., Bilde, M., Facchini, M. C., Decesari, S., Fuzzi, S., Zhou, J., Mønster, J., and Rosenørn, T.: Hygroscopic growth and critical supersaturations for mixed aerosol particles of inorganic and organic compounds of atmospheric relevance, Atmos. Chem. Phys., 6, 1937-1952, doi:10.5194/acp-6-1937-2006, 2006.

Svenningsson, B. and Bilde, M.: Relaxed step functions for evaluation of CCN counter data on size-separated aerosol particles, J. Aerosol Sci., 39, 592-608, doi:10.1016/j.jaerosci.2008.03.004, 2008.

Tate, S. S., Grzybowski, A. K., and Datta, S. P.: Acid dissociations of keto and enol isomers of oxaloacetic acid at $25^{\circ}$, J. Chem. Soc., 1372-1380, 1964.

Varga, Z., Kiss, G., and Hansson, H.-C.: Modelling the cloud condensation nucleus activity of organic acids on the basis of surface tension and osmolality measurements, Atmos. Chem. Phys., 7, 4601-4611, doi:10.5194/acp-7-4601-2007, 2007.

von Pechmann, H.: Über die acetondicarbonsäure, Chem. Ber., 17, 2542-2543, 1884.

Wang, H., Kawamura, K., and Yamazaki, K.: Water-soluble dicarboxylic acids, ketoacids and dicarbonyls in the atmospheric aerosols over the southern ocean and western pacific ocean, J. Atmos. Chem., 53, 43-61, doi:10.1007/s10874-006-1479-4, 2006.

Wiig, E. O.: Carbon dioxide cleavage from acetone dicarboxylic acid, J. Phys. Chem., 32, 961-981, doi:10.1021/j150289a001, 1928.

Wiig, E. O.: Acetonedicarboxylic acid as a leavening agent, Ind. Eng. Chem., 21, 1145-1146, doi:10.1021/ie50239a046, 1929.

Yaws, C. L.: The Yaws handbook of physical properties for hydrocarbons and chemicals, Gulf Publishing Company, Houston, Texas, 2005.

Yokouchi, Y. and Ambe, Y.: Characterization of polar organics in airborne particulate matter, Atmos. Environ., 20, 1727-1734, doi:10.1016/0004-6981(86)90121-6, 1986.

Young, K. C. and Warren, A. J.: A reexamination of the deriviation of the equilibrium supersaturation curve for soluble particles, J. 
Atmos. Sci., 49, 1138-1143, 1992.

Zardini, A. A., Krieger, U. K., and Marcolli, C.: White light Mie resonance spectroscopy used to measure very low vapor pressures of substances in aqueous solution aerosol particles, Opt. Express, 14, 6951-6962, doi:10.1364/OE.14.006951, 2006.

Zardini, A. A., Sjogren, S., Marcolli, C., Krieger, U. K., Gysel, M., Weingartner, E., Baltensperger, U., and Peter, T.: A combined particle trap/HTDMA hygroscopicity study of mixed inorganic/organic aerosol particles, Atmos. Chem. Phys., 8, 55895601, doi:10.5194/acp-8-5589-2008, 2008.
Zardini, A. A. and Krieger, U. K.: Evaporation kinetics of a nonspherical, levitated aerosol particle using optical resonance spectroscopy for precision sizing, Opt. Express, 17, 4659-4669, doi:10.1364/OE.17.004659, 2009.

Zhang, S. H., Seinfeld, J. H., and Flagan, R. C.: Determination of particle vapor pressures using the tandem differential mobility analyzer, Aerosol Sci. Tech., 19, 3-14, doi:10.1080/02786829308959616, 1993. 